\title{
Flow and sediment transport induced by a plunging solitary wave
}

Sumer, B. Mutlu; Sen, M.Berke; Karagali, Ioanna; Ceren, Barkin; Fredsøe, Jørgen; Sottile, Matteo; Zilioli, L.; Fuhrman, David R.

Published in:

Journal of Geophysical Research: Atmospheres

Link to article, DOI:

10.1029/2010JC006435

Publication date:

2011

Document Version

Publisher's PDF, also known as Version of record

Link back to DTU Orbit

Citation $(A P A)$ :

Sumer, B. M., Sen, M. B., Karagali, I., Ceren, B., Fredsøe, J., Sottile, M., Zilioli, L., \& Fuhrman, D. R. (2011).

Flow and sediment transport induced by a plunging solitary wave. Journal of Geophysical Research:

Atmospheres, 116(1), C01008. https://doi.org/10.1029/2010JC006435

\section{General rights}

Copyright and moral rights for the publications made accessible in the public portal are retained by the authors and/or other copyright owners and it is a condition of accessing publications that users recognise and abide by the legal requirements associated with these rights.

- Users may download and print one copy of any publication from the public portal for the purpose of private study or research.

- You may not further distribute the material or use it for any profit-making activity or commercial gain

- You may freely distribute the URL identifying the publication in the public portal 


\title{
Flow and sediment transport induced by a plunging solitary wave
}

\author{
B. Mutlu Sumer, ${ }^{1}$ M. Berke Sen, ${ }^{1,2}$ Ioanna Karagali, ${ }^{1,3}$ Barkin Ceren, ${ }^{1,2}$ Jørgen Fredsøe, ${ }^{1}$ \\ Matteo Sottile, ${ }^{1}$ Luca Zilioli, ${ }^{1}$ and David R. Fuhrman ${ }^{1}$ \\ Received 28 May 2010; revised 8 October 2010; accepted 19 October 2010; published 20 January 2011.
}

[1] Two parallel experiments involving the evolution and runup of plunging solitary waves on a sloping bed were conducted: (1) a rigid-bed experiment, allowing direct (hot film) measurements of bed shear stresses and (2) a sediment-bed experiment, allowing for the measurement of pore water pressures and for observation of the morphological changes. The two experimental conditions were kept as similar as possible. The experiments showed that the complete sequence of the plunging solitary wave involves the following processes: shoaling and wave breaking; runup; rundown and hydraulic jump; and trailing wave. The bed shear stress measurements showed that the mean bed shear stress increases tremendously (with respect to that in the approaching wave boundary layer), by as much as a factor of 8 , in the runup and rundown stages, and that the RMS value of the fluctuating component of the bed shear stress is also affected, by as much as a factor of 2 , in the runup and hydraulic jump stages. The pore water pressure measurements showed that the sediment at (or near) the surface of the bed experiences upward directed pressure gradient forces during the down-rush phase. The magnitude of this force can reach values as much as approximately $30 \%$ of the submerged weight of the sediment. The experiments further showed that the sediment transport occurs in the sheet flow regime for a substantial portion of the beach covering the area where the entire sequence of the wave breaking takes place. The bed morphology is explained qualitatively in terms of the measured bed shear stress and the pressure gradient forces.

Citation: Sumer, B. M., M. B. Sen, I. Karagali, B. Ceren, J. Fredsøe, M. Sottile, L. Zilioli, and D. R. Fuhrman (2011), Flow and sediment transport induced by a plunging solitary wave, J. Geophys. Res., 116, C01008, doi:10.1029/2010JC006435.

\section{Introduction}

[2] There is a renewed interest in sedimentary processes within the inner surf and swash zones, which govern the exchange of sand between the emerged and submerged portions of the beach, and are therefore largely responsible for shoreline configurations. Reviews of various swash zone processes can be found in the recent publications of Butt and Russell [2000], Elfrink and Baldock [2002], Masselink and Puleo [2006], and Brocchini and Baldock [2008]. A canonical problem that has often been studied in the literature, having relevance to these processes, is the runup of breaking solitary waves on a sloping beach. (We note that while wave basin studies involving solitary waves have often traditionally been motivated by the study of tsunamis, Madsen et al. [2008] have recently pointed out that, when scaled up, such experiments are in fact more likely relevant to wind wave

\footnotetext{
${ }^{1}$ Coastal, Maritime and Structural Engineering, Department of Mechanical Engineering, Technical University of Denmark, Lyngby, Denmark

${ }^{2}$ Now at Grontmij I Carl Bro A/S, Glostrup, Denmark.

${ }^{3}$ Now at Wind Energy Department, Risø National Laboratory for Sustainable Energy, Roskilde, Denmark.

Copyright 2011 by the American Geophysical Union. 0148-0227/11/2010JC006435
}

scales. In terms of specific boundary layer quantities, we add that nondimensional time scales relevant to tsunamis may in fact be reached in oscillating tunnel facilities, for example, as discussed by Fuhrman et al. [2009a, p. 15], if the tunnel halfdepth is taken as analogous to the water depth.)

[3] The hydrodynamics within the evolution, runup, and rundown of solitary waves on sloping beds have been quite extensively studied in previous laboratory experiments [e.g., Synolakis, 1987; Synolakis and Skjelbreia, 1993; Lin et al., 1999; Li and Raichlen, 2001, 2002; Hsiao et al., 2008]. While many of these have focused largely on the runup and rundown processes, a number of recent papers have presented more detailed experimental measurements of additional features. For example, the specific role of the jet in the runup of a plunging solitary wave has been investigated by $L i$ and Raichlen [2003]. Velocity kinematics have been measured by Jensen et al. [2003] and Heller et al. [2005], while turbulence properties under broken solitary waves have been measured by Ting [2006, 2008], extending the author's previous work published in a series of papers on turbulence under broken ordinary oscillatory waves [see, e.g., Ting and Kirby, 1995], as well as by Baldock et al. [2009]. Chang et al. [2009] also present detailed measurements of swash flow velocities and pressures during the runup process. Additionally, Seelam and Baldock [2009] have measured the phaseresolved total bed stress beneath nonbreaking solitary waves 


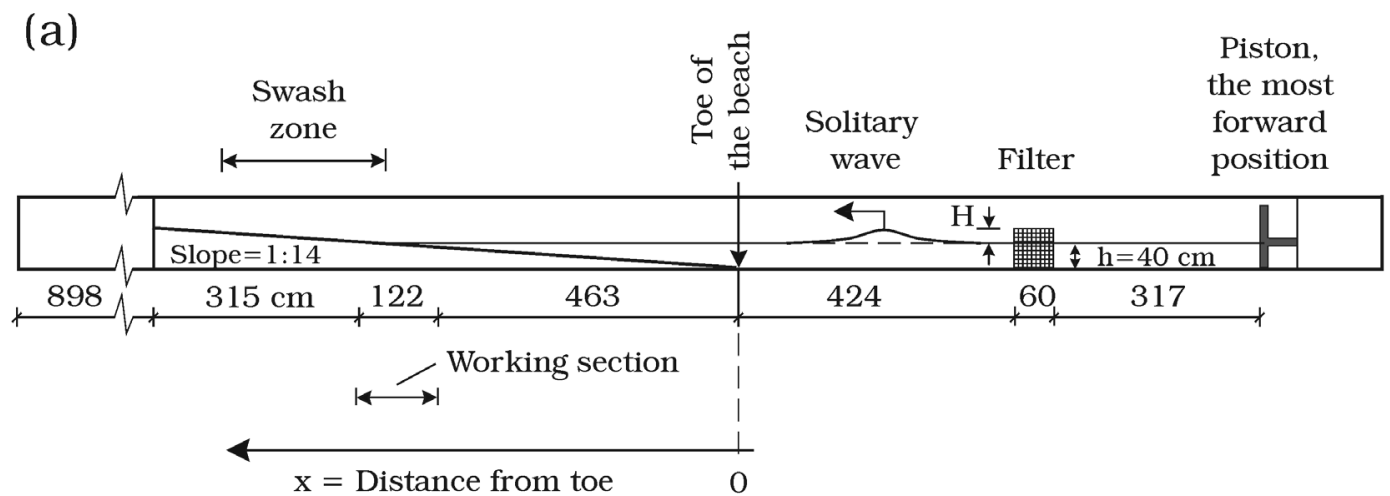

(b)

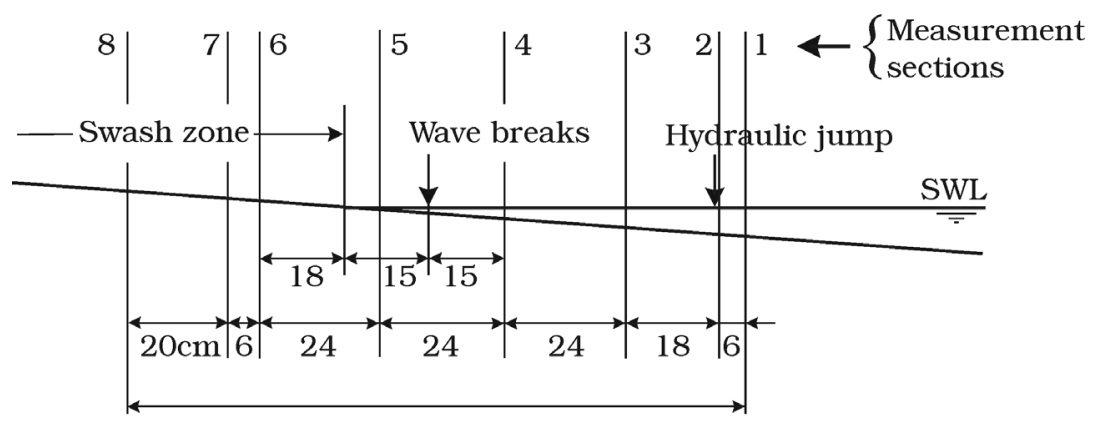

Working section, $122 \mathrm{~cm}$

$\begin{array}{cc}\text { Section } & \begin{array}{c}\text { Distance } \\ \text { from toe } \\ \mathrm{x}(\mathrm{m})\end{array} \\ 1 & 4.63 \\ 2 & 4.69 \\ 3 & 4.87 \\ 4 & 5.11 \\ 5 & 5.35 \\ 6 & 5.59 \\ 7 & 5.65 \\ 8 & 5.85\end{array}$

Figure 1. (a, b) Test setup for the rigid-bed experiments. Longitudinal section. Dimensions are in centimeters.

as well as breaking solitary bores on slopes using a shear cell, although with this method turbulent fluctuations are not resolved. Direct (shear cell) bed shear stress measurements have also been made in bore-driven swash by Barnes et al. [2009]. Studies involving sediment transport mechanisms within the runup of solitary waves are comparatively rare, and appear to be limited to the work of Tonkin et al. [2003], who considered scour from solitary waves around a circular cylinder; Kobayashi and Lawrence [2004], who investigated the cross-shore sediment transport and beach morphology under breaking (both positive and negative) solitary waves; and Young et al. [2010], who investigated the erosion and deposition patterns under breaking positive solitary waves, with additional modeling performed by Xiao et al. [2010]. In related work, Alsina et al. [2009] have presented measurements involving the advection of suspended sediment in the swash zone stemming from solitary broken bores.

[4] The motivation of the present work is add to these studies, by providing an improved understanding of the entire sequence of wave breaking within the context of solitary waves (shoaling, wave breaking, runup, rundown, hydraulic jump, and trailing waves), and especially on the resulting bed shear stresses, sediment transport patterns, and related bed morphology. For this purpose, results of two parallel experiments involving the evolution and runup of plunging solitary waves on a sloping bed will be presented, which are regarded as a simple, idealized means of studying dynamics within isolated breaking wave events (although two processes in ordinary harmonic oscillatory waves are missing in the present idealized case, namely the process controlling the wave setup, and that controlling the water table in the porous seabed of the beach). The first of the two parallel experiments will utilize a rigid bed, allowing, for example, direct (hot film) measurements of bed shear stresses, including their turbulent fluctuations, which are presently lacking in the literature for this class of problem. The second will utilize an erodible bed consisting of fine sand, allowing for the measurement of pore water pressures, pressure gradient forces, as well as for observation of the resulting morphological changes. The two experimental conditions will otherwise be maintained as similar as possible, both in terms of the generated waves and initial bottom configuration, making observations from both sets of experiments easily relatable.

\section{Experimental Setup}

\subsection{Rigid-Bed Experiments}

[5] The rigid-bed experiments were carried out in a wave flume, $28 \mathrm{~m}$ in length, $0.80 \mathrm{~m}$ in depth and $0.60 \mathrm{~m}$ in width. The test setup is illustrated in Figure 1. Solitary waves were produced by a piston-type wave generator. The beach (with a slope of 1:14) was made of PVC plates. The junctions between the side walls of the flume and the PVC plates were sealed to ensure that no exchange of water takes place between the main body of the water and underneath the PVC plates.

[6] Two kinds of measurements were made: bed shear stress measurements and surface elevation measurements. The bed shear stress was measured with a Dantec 55R46 
hot-film probe, mounted flush to the bottom PVC plate. The hot film probe has a hot film sensor, inserted in a quartz rod housed in a $2.1 \mathrm{~mm}$ diameter chromium-plated brass cylinder element. The dimensions of the hot film sensor were $\left(d_{x} \times d_{z}\right)=(0.2 \mathrm{~mm} \times 0.75 \mathrm{~mm})$ in which $x$ is the direction of the wave propagation, and $z$ the transverse direction. To ensure the correct calibration, the hot film was calibrated in position with the help of a three-sided calibration channel ( $1 \mathrm{~mm}$ in depth and $30 \mathrm{~mm}$ in width) placed over the probe with water pumped through the channel. A detailed account of the hot film technique to measure wall shear stresses including the calibration can be found in the work of Sumer et al. [1993]. Briefly, the hot film is calibrated in laminar conditions. For turbulent flows, the calibration relation between the bed shear stress and the voltage drop holds true provided that the bed shear stress in the calibration relation is the instantaneous value of the bed shear stress, and the voltage drop is the instantaneous voltage drop [Hanratty and Campbell, 1983]. The latter has been demonstrated for unsteady flow environments such as for oscillatory boundary layers [Jensen et al., 1989; Lodahl et al., 1998] or for boundary layers under solitary motion [Sumer et al., 2010].

[7] The bed shear stress measurements were made at eight sections (Figure 1b), with sections 1-4 located at the offshore side of the wave breaking, and sections 5- 8 at the onshore side of the wave breaking, sections 6- 8 being in the intermittently wet-dry area. Measurements were carried out only at one section at a time. This is due to the small number of hot-film probes available at the time. (These probes, expensive in price, are highly fragile, and therefore only one probe was used at a time while the remaining few ones were kept as spare probes, to ensure the completion of the test program.) As the hot film does not sense the direction of the bed shear stress, synchronized velocity measurements were made at $y=0.4 \mathrm{~mm}$ ( $y$ being the vertical distance from the bed) just above the hot-film probe, in order to monitor the direction of the bed shear stress, using a Laser Doppler Anemometer (LDA) equipment, along the same lines as in the work of Sumer et al. [2010].

[8] The surface elevation measurements were made at three sections in each test, namely at the filter section (Figure 1a), at the toe section, and at the section where the bed shear stress measurement was made. Conventional wave gages were used in the measurements. The bed shear stress measurements and the surface elevation measurements were synchronized.

[9] In addition to the above mentioned measurements, synchronized flow visualizations were also performed, using a digital video recorder. The synchronization was achieved by a light emitting diode. With this, the observed features of the breaking process (wave breaking, runup, rundown, hydraulic jump, and trailing waves) were related to the measured bed shear stress.

\subsection{Sediment-Bed Experiments}

[10] The sediment-bed experiments were carried out in another flume, $28 \mathrm{~m}$ in length, $1 \mathrm{~m}$ in depth and $4.0 \mathrm{~m}$ in width. Similar to the rigid-bed experiments, solitary waves were produced by a piston type wave generator. The beach (with exactly the same slope as in the rigid-bed experiments, namely $1: 14$ ) was formed with sand, the grain size being $d_{50}=0.18 \mathrm{~mm}$ and the geometric standard deviation $\sigma_{g}\left(=\sqrt{d_{84} / d_{16}}\right)=1.6$. The sand bed thickness was practically nil at the toe while it was $64 \mathrm{~cm}$ at the end of the beach, $8.95 \mathrm{~m}$ from the toe.

[11] Three kinds of measurements were made: pore water pressure measurements, surface elevation measurements, and bed profile measurements. The pore water pressure measurements were made at eight sections. The locations of these sections were the same as those of the hot-film measurements, and these sections were designated by the same symbols, sections $1-8$, displayed in Figure $1 \mathrm{~b}$. The sand bed thickness was $33 \mathrm{~cm}$ at section 1 , and $42 \mathrm{~cm}$ at section 8 . The pore water pressure was measured at five depths at all eight sections, $y=0,-3.5,-6.5,-11.5$ and $-16.5 \mathrm{~cm}$ in the middle of the flume in which $y$ is the distance from the bed surface ( $y$ axis directed upwards). Clearly, this setting differs from that on a real beach where the bed thickness is "infinitely" large. This may influence percolation processes in the seabed. However, in order to offset the unfavorable effect of the finite sediment-bed thickness, the experiments were designed such that the bed thickness was not excessively small across the working section. It may also be noted that the effect of finite thickness of the sediment bed is expected not to be very significant on the pore water pressure gradient near/at the surface of the bed, the quantity we are essentially interested in.

[12] The pore-pressure measurements were made, using Honeywell RS395 pressure transducers. Pressure tappings, $5 \mathrm{~mm}$ in diameter and covered with $40 \mu \mathrm{m}$ nylon filters, were placed on a vertical rack, made of aluminum, long strip (30 mm wide and $3.2 \mathrm{~mm}$ thick) where holes were drilled to accommodate the pressure tappings. The pressure rack continued as a $1 \mathrm{~cm}$ diameter circular rod outside the sediment bed. The pressure tappings were connected to the pressure transducers with transparent, plastic piezometer tubes (OD $=5 \mathrm{~mm}$, and ID $=3 \mathrm{~mm}$ ). The fact that (1) the tubes had a large wall thickness and (2) they were made of hard material ensured that the measured pressures were unaffected by pressure variations. Utmost care was taken to get rid of air bubbles in the tubes, and in the measuring system. Time response of the pressure transducers was checked against the water-surface-elevation time series. These measurements showed that there was no phase delay between the pressure time series at the bed surface and the surface elevation time series. The measurements also showed that that there was no amplification or damping in the response. (We note that Nielsen and Dunn [1998] give a detailed review of frequency response of piezometer tubes for coastal hydrodynamics applications.)

[13] The present experiments were conducted during the first half of 2008. The sand had been placed in the flume for another study in the beginning of 2006, two years before the present campaign, and therefore was practically air free. The latter is important for pore pressure gradient measurements (see, e.g., Sumer and Fredsøe [2002, Figure 10.2] and related text). To further check this, the pore water pressure was measured near the bed surface (at $y=-3.5 \mathrm{~cm}$ and at $y=$ $-6.5 \mathrm{~cm}$ ) under ordinary sinusoidal waves, and compared with the pore water pressure calculated from $\mathrm{Mei}$ and Foda's [1981] theory. (Sumer and Fredsøe [2002, p. 485] can also be consulted for the latter theory.) The input parameters for the calculations were: The porosity, $n=0.4-0.5$ (measured); the coefficient of permeability, $k=3.5 \times$ 
$10^{-3} \mathrm{~cm} / \mathrm{s}$ (measured); Young's modulus of elasticity $E=$ $(1-3) \times 10^{5} \mathrm{kN} / \mathrm{m}^{2}$ (the range, not measured, but assumed in accordance with the values given for soil type "screened crushed quartz, fine angular" of Lambe and Whitman [1969, Table 12.4]); and Poisson's ratio, $\nu=$ 0.35 . This comparison exercise indicated that the degree of saturation, $S_{r}$, varied in the range $0.99-1.00$ for which the measurements matched with the calculated pore water pressures. This result further demonstrated that the sand was practically air free, and therefore the measurements of pore pressure gradient was free of air content of the seabed. At this junction, we add that measurements of air/gas content are still a challenge in the field of soil mechanics, and no generally accepted method exists today to measure air/gas content (a comprehensive review can be found in the work of [Sandven et al., 2007]). Since the subject is beyond the scope of the present study, it will not be pursued further.

[14] Similar to the rigid-bed experiments, the surface elevation measurements were made at three sections in each test, namely at the filter section located at the same section as that in the rigid-bed experiments (Figure 1a), at the toe section, and at the section where the pore water pressure measurements were made. The pore water pressure measurements and the surface elevation measurements were synchronized.

[15] The bed profile was measured in the middle of the flume, using a point gage. In order to obtain a better accuracy in the measurement of the bed profile, the bed was subjected to four successive waves (rather than one single wave) but interrupted with long breaks, and the cumulative effect of the latter was eventually measured as the bed profile. (Even with four waves, the change in the bed elevation with respect to the initial bed profile was only $\mathrm{O}(1 \mathrm{~cm})$, as will be seen later.) It was felt that the bed profile measurement with four waves instead of using a single wave was not a problem, as the main idea in this test was to relate the change in the bed topography to the bed shear stress and pore water pressure measurements.

\section{Test Conditions}

\subsection{Rigid-Bed Experiments}

[16] The offshore water depth in the test was $h=40 \mathrm{~cm}$, and the height of the solitary wave (measured from the still water level, SWL, Figure 1) was $H=7.1 \mathrm{~cm}$, with the offshore surface elevation given by the small-amplitude solitary wave theory,

$$
\eta=H \operatorname{sech}^{2}(\omega t)
$$

in which $\omega$ is

$$
\omega=\sqrt{\frac{3}{4} g H} \frac{1}{h}
$$

where $t$ is time and $g$ is the acceleration due to gravity. Similar to sinusoidal waves, a time scale can be defined by

$$
T=\frac{2 \pi}{\omega}=2 \pi \sqrt{\frac{4}{3 g H}} h,
$$

which can be interpreted as the time scale characterizing the width of the surface elevation time series. This quantity in the experiments was $T=3.48 \mathrm{~s}$.

[17] The sampling frequency of the measurements was $70 \mathrm{~Hz}$. The number of runs for each measurement section was 40 , and therefore the total number of runs conducted at eight sections was 320 . A sensitivity analysis carried out for the present tests indicated that the statistical properties of the measured quantities, the mean value and the standard deviation, converged to constant values for a sample size of 40 waves.

[18] The waves were reproducible. This was tested by plotting twenty, arbitrarily selected time series of the surface elevation (at the toe of the beach) on top of each other, and checked whether or not these time series collapsed on a single curve. This exercise showed that this was indeed the case.

\subsection{Sediment-Bed Experiments}

[19] The test conditions were exactly the same as in the rigid-bed experiments except that the bed in the sediment-bed experiments was sand. This enabled us to relate the sediment transport to the bed shear stress measured in the rigid-bed experiments.

[20] The sampling frequency of the pore water pressure measurements was $20 \mathrm{~Hz}$, a frequency smaller than that for the bed shear stress measurements. This is partly to avoid noise in the pressure signals, and partly to avoid excessive data storage, as the pressure measurements essentially required $\mathrm{O}(10)$ times as much space as the bed shear stress measurements. (Our main interest was not the pore water pressure itself, but rather the pore water pressure gradient in the vertical direction, which has lead to considerably larger data storage.)

[21] The number of runs for each measurement section was 40, and therefore the total number of runs conducted at eight sections was 320. Similar to the rigid-bed experiments, here too, a sensitivity analysis showed that the statistical properties of the measured quantities, the mean value and the standard deviation, converged to constant values for a sample size of 40 waves.

[22] In the experiments, the 40 waves for each section were not run repeatedly, but rather four waves were run repeatedly (interrupted with periods for the water to come to a complete rest), and then the flume was stopped, and the bed was leveled off, and subsequently another set of four waves were run, and the procedure was repeated until the entire set of the total 40 runs were completed at the measurement section in consideration. Ideally the bed should be leveled off after each run. However, this required each time to stop the flume and drain it, to level off the bed, and to fill the flume to conduct a new run. Clearly this would have caused an enormous amount of time to perform the total 320 runs, and therefore, as a trade off, it was decided to do the latter exercise every four runs.

\section{Results of Rigid-Bed Experiments}

\subsection{Description of Breaking Wave}

[23] Figure 2 schematically illustrates the complete sequence of the breaking solitary wave observed in the present experiments (where the breaking was of plunging type): shoaling 
(a) Shoaling and wave breaking

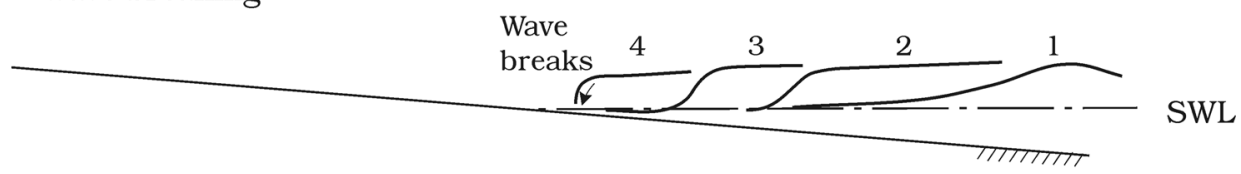

(b) Runup
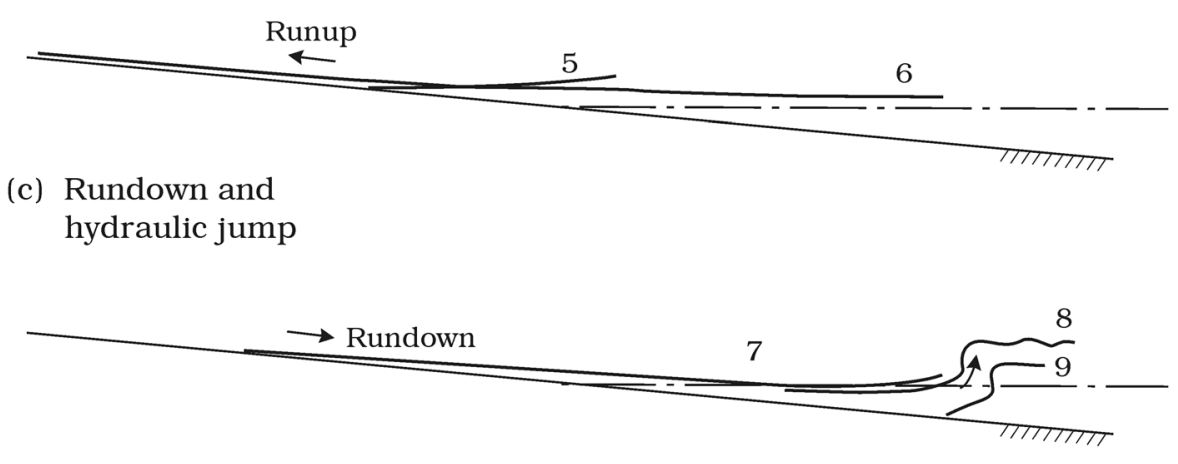

(d) Trailing wave

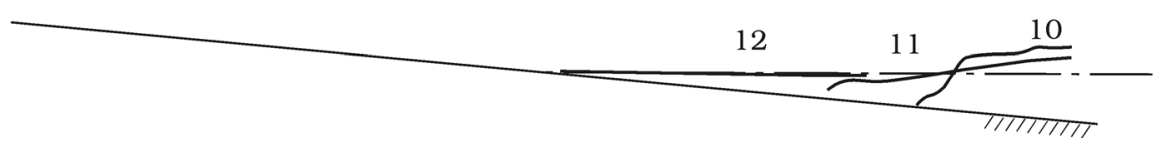

Figure 2. (a-d) Sequence of the solitary wave breaking. Small numbers denote different stages of the process.

and wave breaking (Figure 2a), runup (Figure 2b), rundown and hydraulic jump (Figure 2c), and trailing wave (Figure 2d). (Numbers in Figures 2a-2d denote different stages of the breaking process.) The plunging wave breaking occurs with the wave curling over forward and impinging onto the water surface onshore with a small amount of air trapped inside the "tube" formed by the wave crest.

[24] The maximum runup elevation from SWL was measured to be $R=18 \mathrm{~cm}$. This compares well with a value $R=18.9 \mathrm{~cm}$ predicted by the empirical expression of Fuhrman and Madsen [2008]:

$$
\frac{R}{H}=3.9 \xi_{s}^{0.42}, \quad \xi_{s}=\frac{s}{H / h}
$$

based on various experimental measurements. Here $s$ is the beach slope and $\xi_{s}$ is the so-called solitary wave surf similarity parameter, which was reduced to an elementary form based on the concept originally presented by Kobayashi and Karjadi [1994]. It is stressed that the parameter $\xi_{s}$ is analogous to the parameter $\xi=s / \sqrt{H / L_{0}}$ for regular waves, which is commonly used to parameterize their runup, where $L_{0}=g T^{2} /(2 \pi)$ is the deep-water wavelength. It would not, however, necessarily be expected to predict wave breaker types, which are typically characterized on the basis of a surf similarity parameter defined in terms of the deep-water wave height $H_{0}$, that is, $\xi_{0}=s / \sqrt{H_{0} / L_{0}}$. Alternatively, breaker types for solitary waves have been directly charac- terized by Grilli et al. [1997] using a so-called slope parameter:

$$
S_{0}=1.521 \frac{s}{\sqrt{H / h}} .
$$

Invoking the present values yields $S_{0}=0.26$, which is indeed within their suggested plunging breaker regime $\left(0.025<S_{0}<0.30\right)$. Hence, the present observations are reasonably in line with previous work, in terms of both the runup and breaker type.

[25] Figure 3 displays the time series of the surface elevation $\eta$ at different measurement sections, sections 1, 3, 5 and 8 , along with that at the toe of the beach. The time series for sections 2, 4, 6 and 7 are not included in

Figure 3 for reasons of space. The origin of time, $t=0$, is taken as the instant where the wave crest passes the toe section (Figure 1a). In order to picture the various stages of the wave breaking represented in Figure 3, and relate them to Figure 2, we recall that sections 1 and 3 (Figure 1) are located at the offshore side, and sections 5 and 8 (Figure 1) at the onshore side of the breaking point (Figure 2a). The following observations can be made from Figure 3 .

[26] 1. The shoaling (Figure 1a), which takes place until the wave breaks just before section 5, is clearly observed from Figure $3 \mathrm{a}-3 \mathrm{c}$.

[27] 2. The signal corresponding to section 1 (Figure 3b) begins to oscillate, starting with time $t \cong 7 \mathrm{~s}(\mathrm{~J}$ in Figure $3 \mathrm{~b}$ ). The synchronized video recordings reveal that these oscillations are due to the hydraulic jump following the rundown 


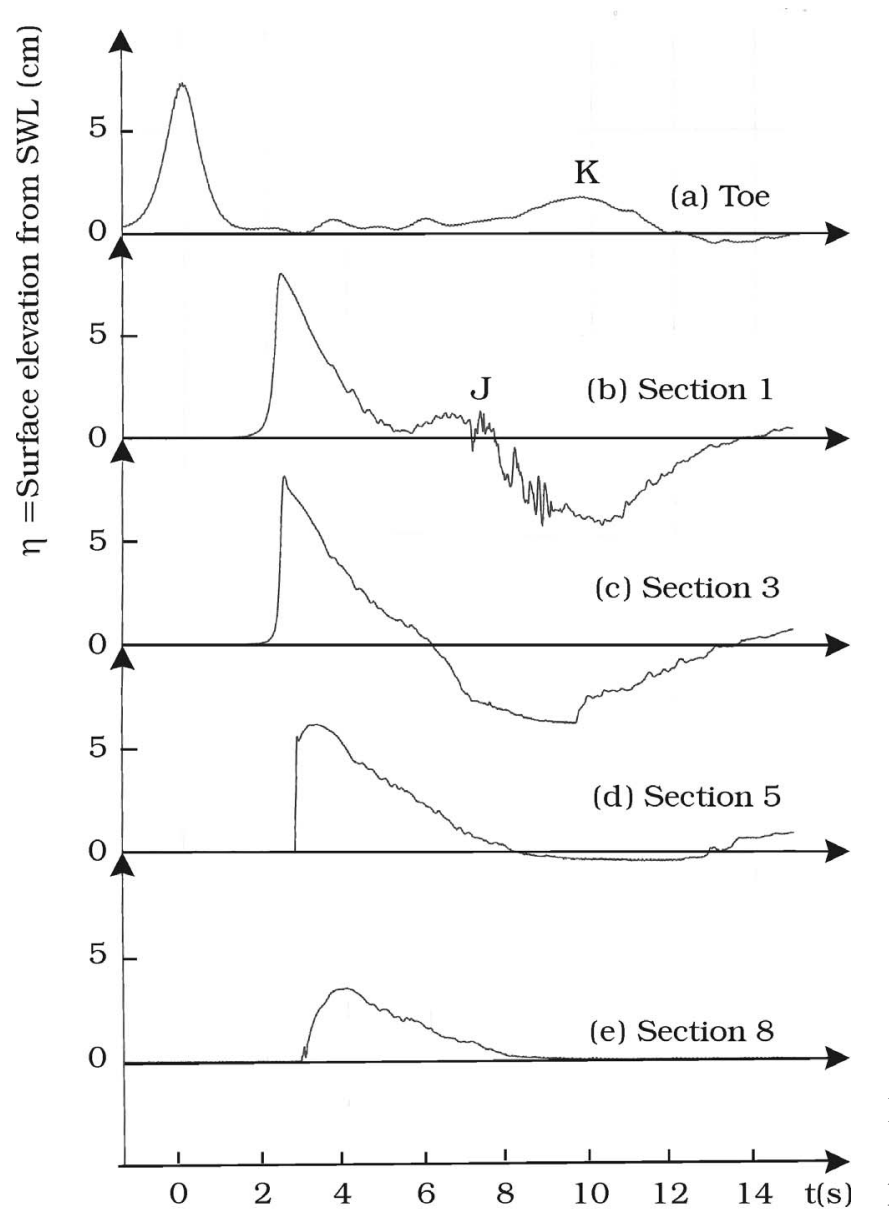

Figure 3. (a-e) Time series of the surface elevation at different sections. The $\eta$ at the toe section satisfies equation (1) for times $t \approx 2 s$.

stage (Figure 2c). The wave generated by the hydraulic jump travels offshore, and the crest of this wave arrives at the toe of the beach at time $t=9.5 \mathrm{~s}$ (marked $\mathrm{K}$ in Figure $3 \mathrm{a}$ ).

[28] 3. The runup and rundown stages of the process at the measurement sections are evident from the time series in Figures $3 b-3 e$. Regarding the time series recorded at section 8 , as this section is in the intermittently wet- dry area, the signal is cut for small and large times, namely, for $t<3 \mathrm{~s}$ and for $t>8 \mathrm{~s}$.

\subsection{Bed Shear Stress}

[29] Figure 4 presents the time variation of the mean bed shear stress while Figure 5 presents that of the RMS value of the fluctuating component of the bed shear stress $\tau_{0}^{\prime}=\tau_{0}-$ $\overline{\tau_{0}}$ at sections $1,2,5,6$, and 8 . Note that the bed shear stress data are plotted in Figures 4 and 5 in terms of $\overline{\tau_{0}}(t) / \rho$ and $\left(\left(\tau_{0}^{\prime}\right)^{2}\right)^{1 / 2} / \rho$ for convenience. Here $\rho$ is the density of water. The mean value of the bed shear stress is calculated through ensemble averaging according to

$$
\overline{\tau_{0}}(t)=\frac{1}{N} \sum_{j=1}^{N}\left[\tau_{0}(t)\right]_{j}
$$

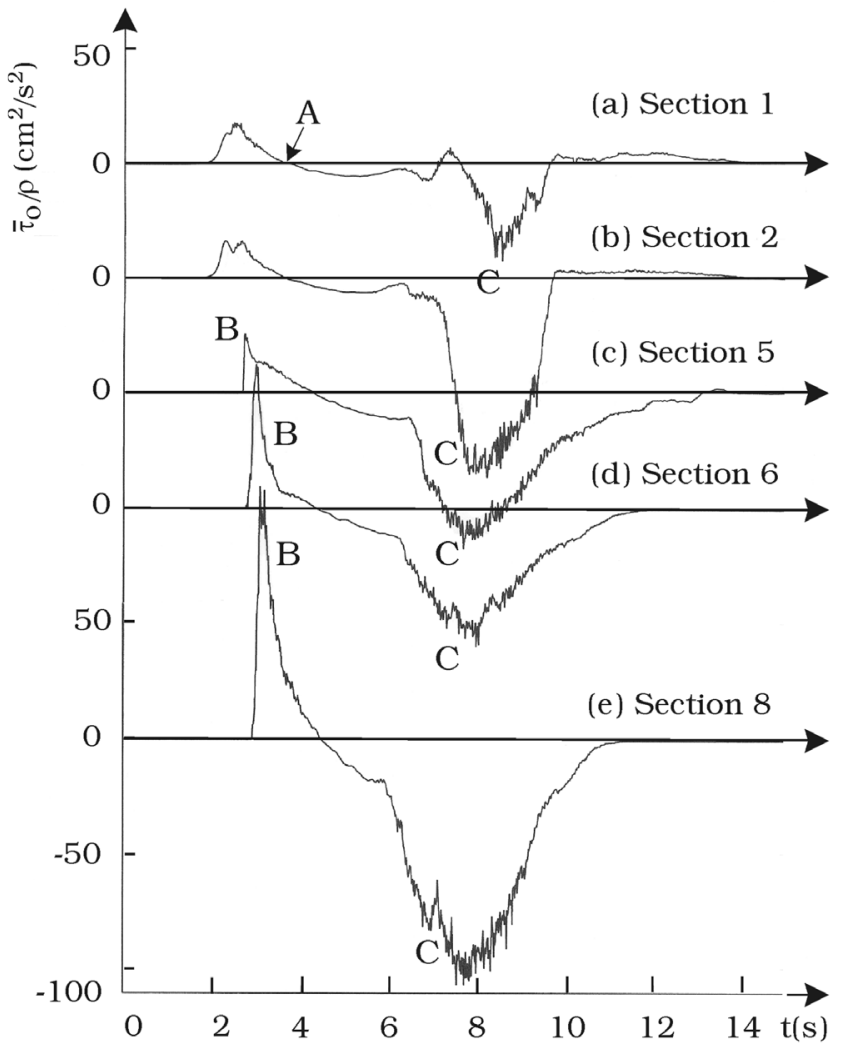

Figure 4. (a-e) Time variation of the mean bed shear stress. The $t=0$ corresponds to the instant the wave crest passes the toe section.

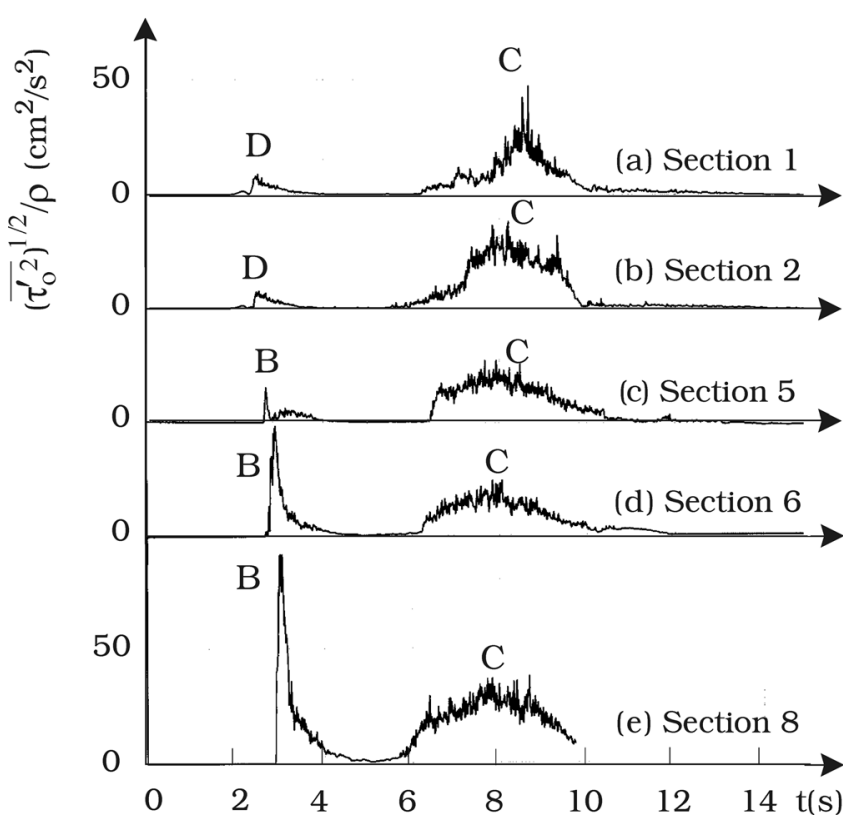

Figure 5. (a-e) Time variation of the RMS value of the fluctuating component of the bed shear stress. The $t=0$ corresponds to the instant the wave crest passes the toe section. 


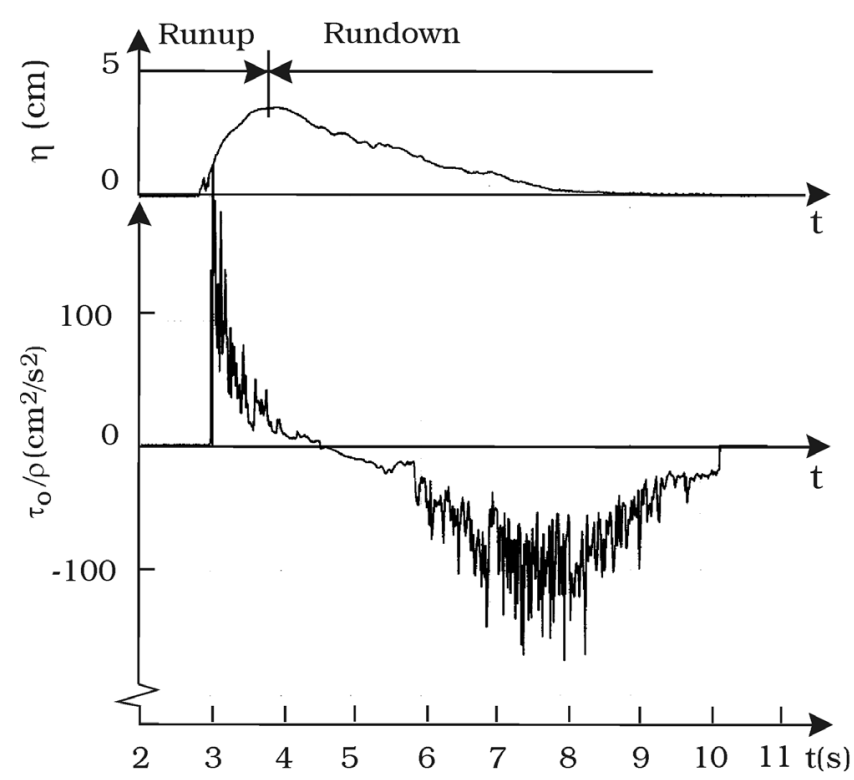

Figure 6. Time series of the surface elevation and bed shear stress at section 8 .

in which $\left[\tau_{0}(t)\right]_{j}$ is the time series of $\tau_{0}$ in run $j$ and $N$ is the number of runs (i.e., the sample size) at that section. The RMS value of the fluctuating component of the bed shear stress, $\tau_{0}^{\prime}=\tau_{0}-\overline{\tau_{0}}$, is calculated by

$$
\left(\overline{\left(\tau_{0}^{\prime}\right)^{2}}\right)^{1 / 2}(t)=\left\{\frac{1}{N-1} \sum_{j=1}^{N}\left\{\left[\tau_{0}(t)\right]_{j}-\overline{\tau_{0}}(t)\right\}^{2}\right\}^{\frac{1}{2}} .
$$

The way in which the "turbulence" is calculated according to equation (7) requires a very repeatable phase of the wave form, as was indicated by one of the reviewers. This was checked by plotting twenty, arbitrarily selected time series of the surface elevation (at the toe of the beach) on top of each other; it was observed that these time series collapsed on a single curve with RMS differences being nil. (See also the discussion at the end of section 3.1.)

[30] The sign convention in Figure 4 is that the direction of the bed shear stress is positive in the onshore direction. Time $t=0$ in Figures 4 and 5 coincides with the instant where the wave crest passes the toe section, as in Figure 3. The RMS value of the fluctuating component of the bed shear stress exhibited in the bed shear stress (Figure 5) calls for an early discussion about the generation of these fluctuations in the bed shear stress in the present setting.

\subsubsection{Generation Mechanisms of Bed Shear Stress Fluctuations}

[31] We start with section 8 (Figure 5e). There are two peaks in the time variation of $\left(\overline{\left(\tau_{0}^{\prime}\right)^{2}}\right)^{1 / 2}$. The first peak is associated with the runup stage while the second peak (Figure 5e) is associated with the rundown stage, as can be readily seen from the surface elevation $(\eta)$ and bed shear stress $\left(\overline{\tau_{0}}(t) / \rho\right)$ traces in Figure 6 obtained in a single run. For the runup stage, the bed shear stress fluctuations are consistent with a dual generation for turbulence by the wave breaking prior to the runup, and by the turbulence generated by the unsteady boundary layer that develops during the runup. For the rundown stage, they are generated solely by the turbulence generated in the unsteady boundary layer of the down-rush flow (Figure 2c). The previously described picture is qualitatively the same for all sections at the onshore side of the breaking section, sections 5-8 (Figure 5c- 5 e).

[32] Regarding the offshore side of the breaking point (sections 1 and 2 in Figures 5a and 5b, respectively), here, too, there are two peaks in the time variation of $\left(\overline{\left(\tau_{0}^{\prime}\right)^{2}}\right)^{1 / 2}$. The first peak ( $\mathrm{D}$ in Figures $5 \mathrm{a}$ and $5 \mathrm{~b}$ ) is associated with the wave boundary layer experienced at these sections while the second peak is associated with the rundown stage and the hydraulic jump (C in Figures 5a and 5b). Of these, the first peak requires a little more discussion. The bed shear stress trace in Figure 7 shows clearly that the boundary layer flow is not in the laminar regime for the entire cycle of the flow; although $\tau_{0}$ time series shows no sign of turbulence during the acceleration stage, the fluctuations in the signal in the decelerating stage, marked $\mathrm{T}$ in Figure 7 , are quite evident. To check whether or not this is the case, we need to determine the Reynolds number. To this end, a supplementary test was conducted where the vertical distribution of the velocity was measured at section 1, using the same LDA equipment as described in section 2.1. Figure 8 displays the result of this test. The quantity $U_{m}$ in Figure 8 is the maximum value of the water particle velocity. On the basis of $U_{m}$ outside the boundary layer, the half stroke of the water particle displacement in the free-stream region is calculated from

$$
a=\frac{U_{m}}{\omega},
$$

and the Reynolds number, $R e=\frac{a U_{m}}{\nu}$, is found to be $R e=3 \times$ $10^{5}$. This is a transitional-regime Reynolds number, consistent with the recent experimental [Sumer et al., 2010] and numerical [Vittori and Blondeaux, 2008] data compiled by Sumer et al. [2010] in conjunction with the transition to turbulence in solitary wave boundary layers, although the critical Reynolds number is, in the work of Sumer et al. [2010], given as $R e=5 \times 10^{5}$, a slightly higher Reynolds number than the present one. However, the precise value of

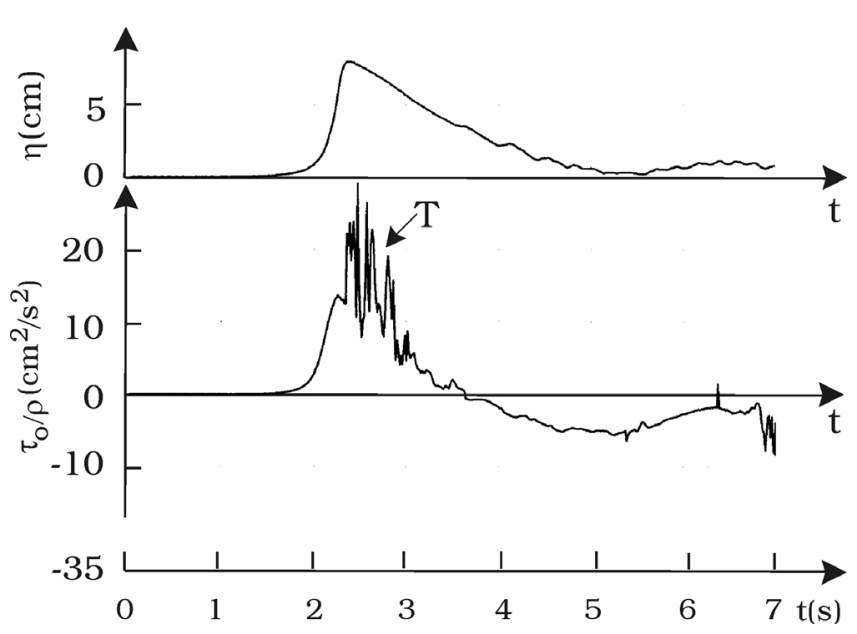

Figure 7. Time series of the surface elevation and bed shear stress at section 1 . 


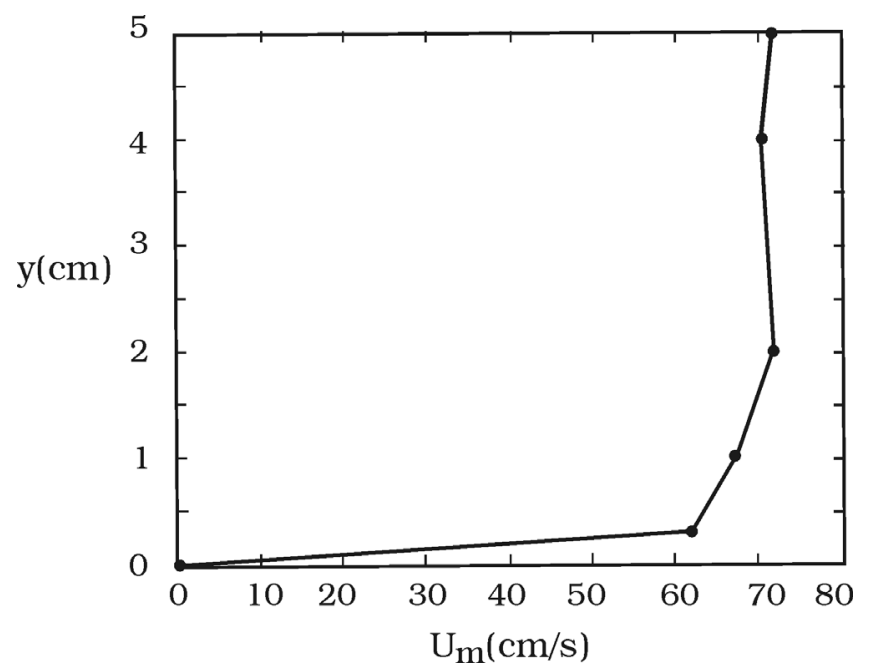

Figure 8. Distribution of the maximum velocity across the depth at section 1 .

the critical Reynolds number in laminar-to-turbulence transition is very difficult to determine, and it also changes from study to study, depending on various factors such as the forcing, the experimental environment, external conditions, protrusions on the boundary, etc. Nevertheless, the fact that the present Reynolds number is very close to the critical Reynolds number reported by Sumer et al. [2010], and the signal presented in Figure 7 undeniably reveals the presence of turbulence in the deceleration period indicate that the present solitary boundary layer is, indeed, not in the laminar regime. Hence one can conclude that the turbulence in connection with the first peak in Figures $5 \mathrm{a}$ and $5 \mathrm{~b}$ is generated by the wave boundary layer. Returning to the mean and the RMS bed shear stress in Figures 4 and 5, each quantity is now considered individually.

\subsubsection{Mean Bed Shear Stress}

[33] The behavior of the mean bed shear stress, $\overline{\tau_{0}}$, at section 1 (Figure 4a) for time $2 s \approx t \approx 6 s$ is typical for a solitary wave boundary layer [e.g., Sumer et al., 2010]. $\overline{\tau_{0}}$ changes direction (marked $\mathrm{A}$ in Figure 4a) during deceleration stage of the solitary boundary layer as the wave continues to propagate in the onshore direction, consistent with the previous research on solitary wave boundary layers [Liu et al., 2007; Vittori and Blondeaux, 2008; Sumer et al., 2010].

[34] For section 1, the measured maximum values of the bed shear stress before and after the reversal of the bed shear stress direction at A are compared with Sumer et al.'s [2010] experiments where the solitary wave boundary layer is simulated with a solitary motion of the water in an oscillating water tunnel. This comparison shows that the present maximum value is a factor of 2 larger than that obtained from Sumer et al.'s [2010] friction factor diagram for the onshoredirected flow, while it is on the same order of magnitude as that obtained from Sumer et al.'s [2010] friction factor diagram for the offshore-directed flow of the boundary layer. The increase in the maximum bed shear stress in the present experiments may be attributed to the fact that the solitary boundary layer in the present case takes place on a slope. As can be seen in section 4.1, free surface time series (Figure 3b), the effect of the sloping bed is to dramatically increase the front-back asymmetry of the wave, leading to a significantly steepened front face relative to the initial symmetric solitary form (Figure 3a). The rapid acceleration to the peak in such a strongly asymmetric wave gives less time for the boundary layer to grow, relative to a pure (front-back symmetric) solitary wave. The result is a smaller boundary layer thickness for the acceleration half-cycle, leading to increased velocity gradients in the boundary layer, and hence an increased maximum bed shear stress. Converging effects created by the slope may also play a role in increasing the bed shear stress. These various effects have not been studied specifically for solitary-type wave boundary layers. However, Fuhrman et al.'s [2009a, 2009b] numerical simulations for oscillatory boundary layers illustrate the influence of these various effects, and the observed increase in the bed shear stress is in qualitative agreement with their simulation results.

[35] Following the breaking, $\overline{\tau_{0}}$ experiences a tremendous increase during the runup stage (marked B in Figures $4 \mathrm{c}-$ $4 \mathrm{e})$, which is due to the combined action of the breaking and the reduction of the flow depth as the flow continues onshore. Of particular interest is the amplification of $\overline{\tau_{0}}$ in the swash zone (section 8 , Figure $4 \mathrm{e}$ ). The increase in $\overline{\tau_{0}}$ with respect to that of the approaching boundary layer flow is like $\mathrm{O}(8)$. This clearly has a large implication for sediment transport in the swash zone.

[36] Similarly, $\overline{\tau_{0}}$ experiences very large values during the rundown stage, as seen from Figures $4 \mathrm{a}-4 \mathrm{e}$, marked $\mathrm{C}$ in Figure 4. In the swash zone, the maximum value attained during the rundown is as large as that measured during the runup (Figure 4e). Here, too, very large values of the bed shear stress imply that the sediment transport during the rundown is expected to increase tremendously. At this junction, we point out that the water depth does not influence the calibration unless the depth becomes so small that the surface tension "kicks in". The precise nature of this effect is unknown to the writers. Nevertheless, from Figures $3 \mathrm{e}$ and $4 \mathrm{e}$, for example, for section 8 , it may be expected that this occurs around $t \sim 10 \mathrm{~s}$, significantly later than the time at which the bed shear stress attains its maximum value.

[37] The behavior of the time variation of $\overline{\tau_{0}}$ in Figure 4, for example, for section 8 exhibits a sudden decrease in the bed shear stress a short while after $\overline{\tau_{0}}$ reverses its direction, at $t=6 \mathrm{~s}$. This can be explained as follows. The way in which $\overline{\tau_{0}}$ varies prior to the flow reversal near the bed until $t=6 \mathrm{~s}$ is much the same as in the case of the solitary wave boundary layer [Liu et al., 2007; Vittori and Blondeaux, 2008; Sumer et al., 2010]. However, beyond $t=6 \mathrm{~s}$, the offshore-directed flow continues like a (unsteady) turbulent boundary layer in an open channel, a process different from the solitary wave boundary layer process, and the flow is in the turbulent regime (see the time series in Figure 6 for the same section, section 8). Hence the behavior of the time variation of $\overline{\tau_{0}}$ in Figure 4 changes around $t=6 \mathrm{~s}$. A similar change can also be observed in Figure 4d, Figure 4c, Figure $4 \mathrm{~b}$, and even in Figure $4 \mathrm{a}$. The sudden change in the behavior of $\overline{\tau_{0}}$ in Figures $4 \mathrm{a}-4 \mathrm{~d}$ is associated with the rundown stage of the wave breaking.

[38] To illustrate the $x$ variation of $\overline{\tau_{0}}$, the maximum values of the mean bed shear stress picked up from Figure 4 


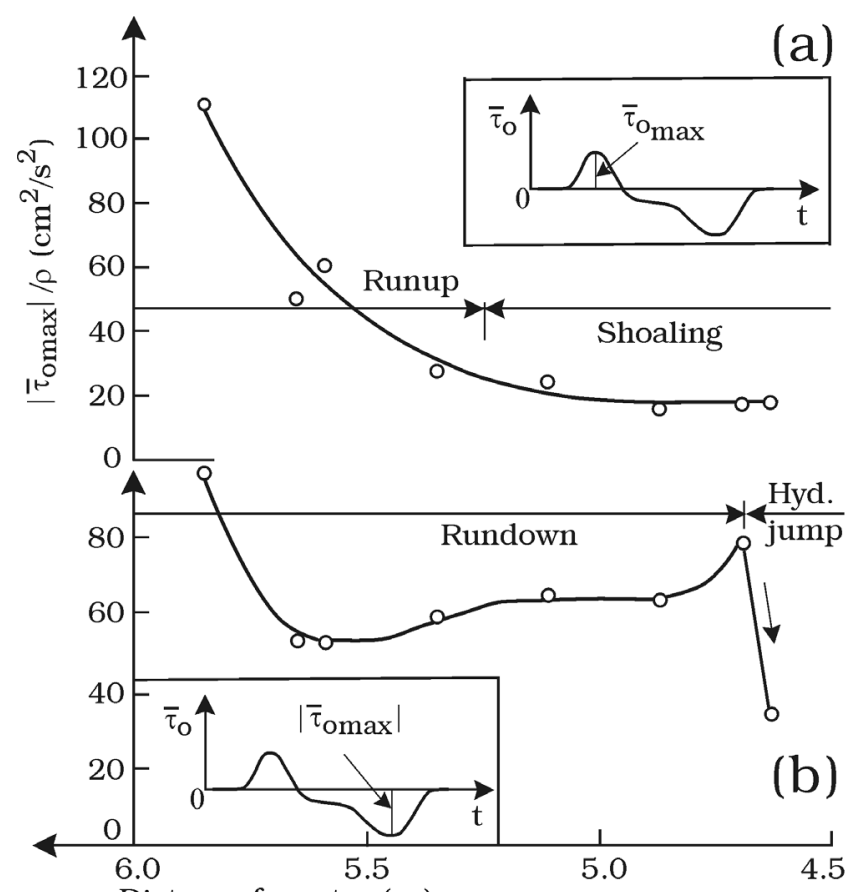

$\mathrm{x}=$ Distance from toe $(\mathrm{m})$

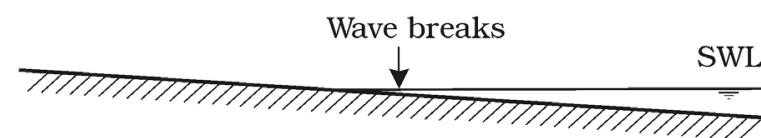

Figure 9. The $x$ variation of the maximum value of the mean bed shear stress (a) during the shoaling and runup stages and (b) during the rundown and hydraulic jump stages.

are plotted in Figure 9. (Data from sections 3, 4 and 7 are also included in Figure 9 for completeness.) Figure 9a corresponds to the shoaling and the runup stages while Figure $9 \mathrm{~b}$ corresponds to the rundown and the hydraulic jump stages. The variations of $\overline{\tau_{0}}$ as function of $x$, and its implications for sediment transport can be interpreted as in the preceding paragraphs.

\subsubsection{RMS Value of Fluctuating Bed Shear Stress}

[39] Turning our attention to the RMS value of the fluctuating component of the bed shear stress, $\left(\overline{\left(\tau_{0}^{\prime}\right)^{2}}\right)^{1 / 2}$, Figure 5, it is seen that it increases massively in the swash zone (section 6 and 8) during runup (Figures $5 \mathrm{~d}$ and 5e, marked B in the Figure 5), and during rundown and hydraulicjump stages (Figures 5a-5e, marked $\mathrm{C}$ ). The generation mechanisms of the fluctuations in the bed shear stress have already been discussed in the preceding paragraphs. We will continue the discussion to address the question how the present data compares with the data from classic boundary layer flows.

[40] In order to compare the present breaking solitary wave data with the corresponding data from boundary layers, the present data are recast in terms of the maximum value of $\left(\overline{\left(\tau_{0}^{\prime}\right)^{2}}\right)^{1 / 2}$, normalized by the corresponding maximum value of $\overline{\tau_{0}}$, and plotted in Figure 10 for the shoaling and runup stages (Figure 10a), and for the rundown and hydraulic jump stages (Figure 10b).
[41] First of all, the normalized $\left(\overline{\left(\tau_{0}^{\prime}\right)^{2}}\right)_{\max }^{1 / 2} / \bar{\tau}_{0} \max$ takes values in the range from 0.2 to 0.4 during shoaling, for $x<$ $5.25 \mathrm{~m}$. The range 0.2 to 0.4 is not radically different from the range $\left(\overline{\left(\tau_{0}^{\prime}\right)^{2}}\right)^{1 / 2} / \overline{\tau_{0}}=0.25-0.40$ reported in conjunction with the current-boundary-layer research [Alfredson et al., 1988; Eckelmann, 1974; Mitchell and Hanratty, 1966, etc.], and that $\left(\overline{\left.\left(\tau_{0}^{\prime}\right)^{2}\right)}\right)_{\max }^{1 / 2} /{\overline{\tau_{0}}}_{\max }=0.25-0.30$ reported in conjunction with the oscillatory-boundary-layer research [Lodahl et al., 1998]. However, it is evident from Figure 10a that, with the wave breaking, followed by the runup, $\left(\overline{\left(\tau_{0}^{\prime}\right)^{2}}\right)_{\max }^{1 / 2} /{\overline{\tau_{0}}}_{\max }$ increases quite significantly, and reaches values as high as 0.85 . Clearly this is the "external" field of turbulence introduced by the wave breaking process.

[42] Secondly, it is seen from Figure $10 \mathrm{~b}$ that $\left(\overline{\left(\tau_{0}^{\prime}\right)^{2}}\right)_{\max }^{1 / 2}$ $\bar{\tau}_{0} \max$ is maintained constant, at the value $\left(\overline{\left(\tau_{0}^{\prime}\right)^{2}}\right)_{\max }^{1 / 2} /{\overline{\tau_{0}}}_{\max }=$ 0.35 , during rundown all the way down to $x=4.7 \mathrm{~m}$ where

(a)
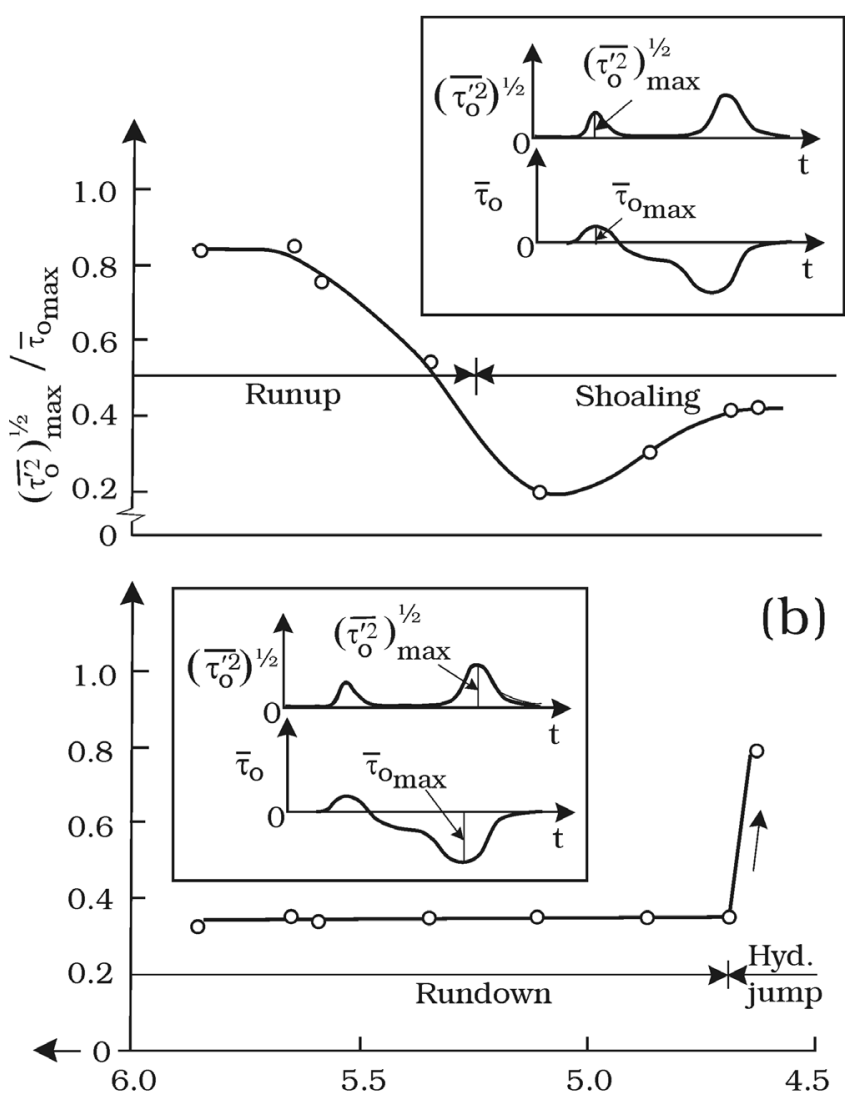

$\mathrm{x}=$ Distance from toe $(\mathrm{m})$

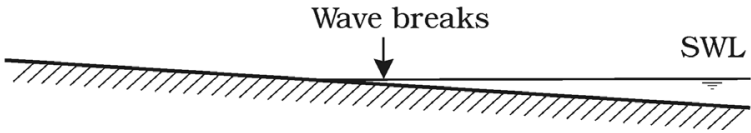

Figure 10. The $x$ variation of the normalized maximum value of the RMS value of the fluctuating component of the bed shear stress (a) during the shoaling and runup stages and (b) during the rundown and hydraulic jump stages. 


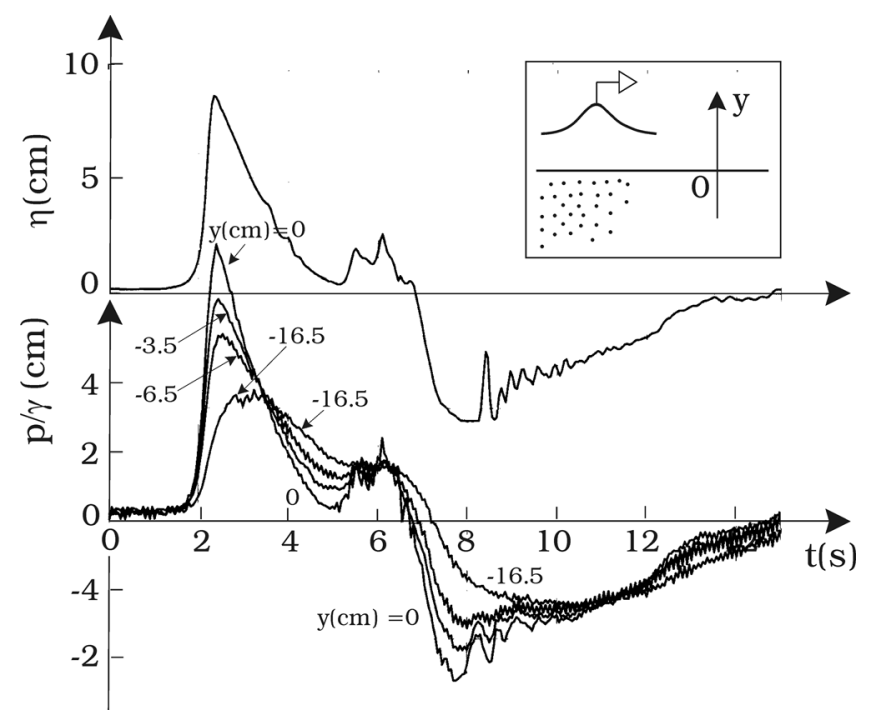

Figure 11. Time series of surface elevation and pore water pressure at different depths $y$ for section 1 .

the flow experiences a hydraulic jump. The value $\left(\overline{\left(\tau_{0}^{\prime}\right)^{2}}\right)_{\max }^{1 / 2} /$ ${\overline{\tau_{0}}}_{\max }=0.35$ is in strikingly good agreement with the previously cited range of turbulence for current boundary layers, namely $\left(\overline{\left(\tau_{0}^{\prime}\right)^{2}}\right)^{1 / 2} / \overline{\tau_{0}}=0.25-0.40$. This supports the argument put forward earlier that the fluctuating shear stress is generated by the turbulent boundary layer process of the down-rush flow during this stage. However, $\left(\overline{\left(\tau_{0}^{\prime}\right)^{2}}\right)_{\max }^{1 / 2} /$ $\bar{\tau}_{0 \text { max }}$ experiences a sudden jump when the down-rush flow eventually undergoes the hydraulic jump at the section $x=$ $4.7 \mathrm{~m}$. (Unfortunately, no measurements were available from the present study for $x$ sections at the offshore side of the hydraulic jump to resolve the turbulence beyond this section.)

\section{Results of Sediment-Bed Experiments}

\subsection{Pore Water Pressure Time Series and Pressure Gradient Forces}

[43] Figure 11 displays the time series of pore water pressure at section 1 for four different depths, along with the time series of the surface elevation, $\eta$, at the same section. (The pore water pressure time series at the depth $y=-11.5 \mathrm{~cm}$ is not included in Figure 11 to keep the time series relatively simple.) In Figure 11, $p$ is the pore water pressure in excess of the static pore water pressure at these depths, and $\gamma$ is the specific weight of water.

[44] When closely inspected, it can be readily seen that there are three different areas in the time-series representation of pore water pressure in Figure 11, each of which gives a different pore pressure distribution in the vertical. These pressure distributions are illustrated in Figure 12 for three characteristic times representative of these areas, one at $t=2.4 \mathrm{~s}$, the second one at $t=4.9 \mathrm{~s}$, and the third one at $t=7.5 \mathrm{~s}$. As seen from Figure 12, the pressure distribution at $t=2.4 \mathrm{~s}$ generates a downward directed pressure gradient force, while the distributions at $t=4.9 \mathrm{~s}$ and $7.5 \mathrm{~s}$ generate upward directed pressure gradient forces in the bed soil. As seen from Figure 12, the gradient of the pressure distribution in all three cases is largest near/at the bed surface, and therefore the previously mentioned downward and upward directed pressure gradient forces on the bed sediment become largest near/at the bed surface.

[45] Both the downward directed pressure gradient and the upward directed pressure gradient are caused by the delay in the pore pressure in responding to the fluid loading, as can be readily seen from the time series in Figure 11. The delay itself is linked largely to the time associated with infiltration and exfiltration processes. In this context, we also note that there is quite a substantial amount of literature on the soil stress and pore pressure response of poroelastic beds and the influence of the gas content; see, for example, the detailed account given by Sumer and Fredsøe [2002] (chapter 10 for the soil response, and pp. 448-450 and pp. 483-487 of the same reference for the influence of gas content).

[46] Figure 13 illustrates the time variation of the mean pressure gradient at the surface layer of the bed for five different measurement sections. The pressure gradient is upward directed when $\left(-\frac{\partial p}{\partial v}\right)>0$. The statistical properties of the pressure gradient, the mean value and the standard deviation, are calculated in the same way as in equations (6) and (7). sections 3, 5 and 7 are not included in Figure 13

for reasons of space. In contrast to Figures 4 and 5, section 4 is included in Figure 13 in favor of section 5, to better illustrate the way in which the pressure gradient variations change with $x$. (The standard deviation calculations show that the standard deviation values are found to be like $\sigma_{\partial(p / \gamma) / \partial / \gamma}=$ $O(0.05)$, and practically independent of the location of the measurement section.)

[47] Similar to Figure 9, the maximum values of the mean pressure gradients picked up from Figure 13 are plotted in Figure 14, to illustrate the variation of $\left(-\frac{\partial p}{\partial y}\right)_{\max }$ with $x$. Data from sections 3,5 and 7 are also included in

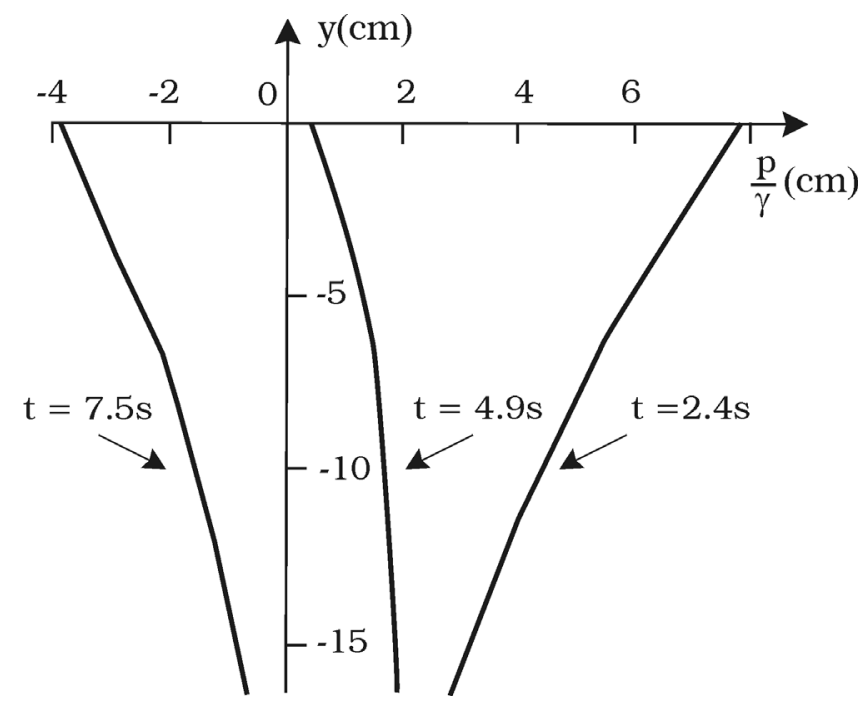

Figure 12. Distributions of pore water pressure across the bed soil depth at three different times $t$ for section 1 . The pressure distribution at $t=2.4 \mathrm{~s}$ generates a downward directed pressure gradient force, while the distributions at $t=$ $4.9 \mathrm{~s}$ and $7.5 \mathrm{~s}$ generate upward directed pressure gradient forces in the bed soil. 


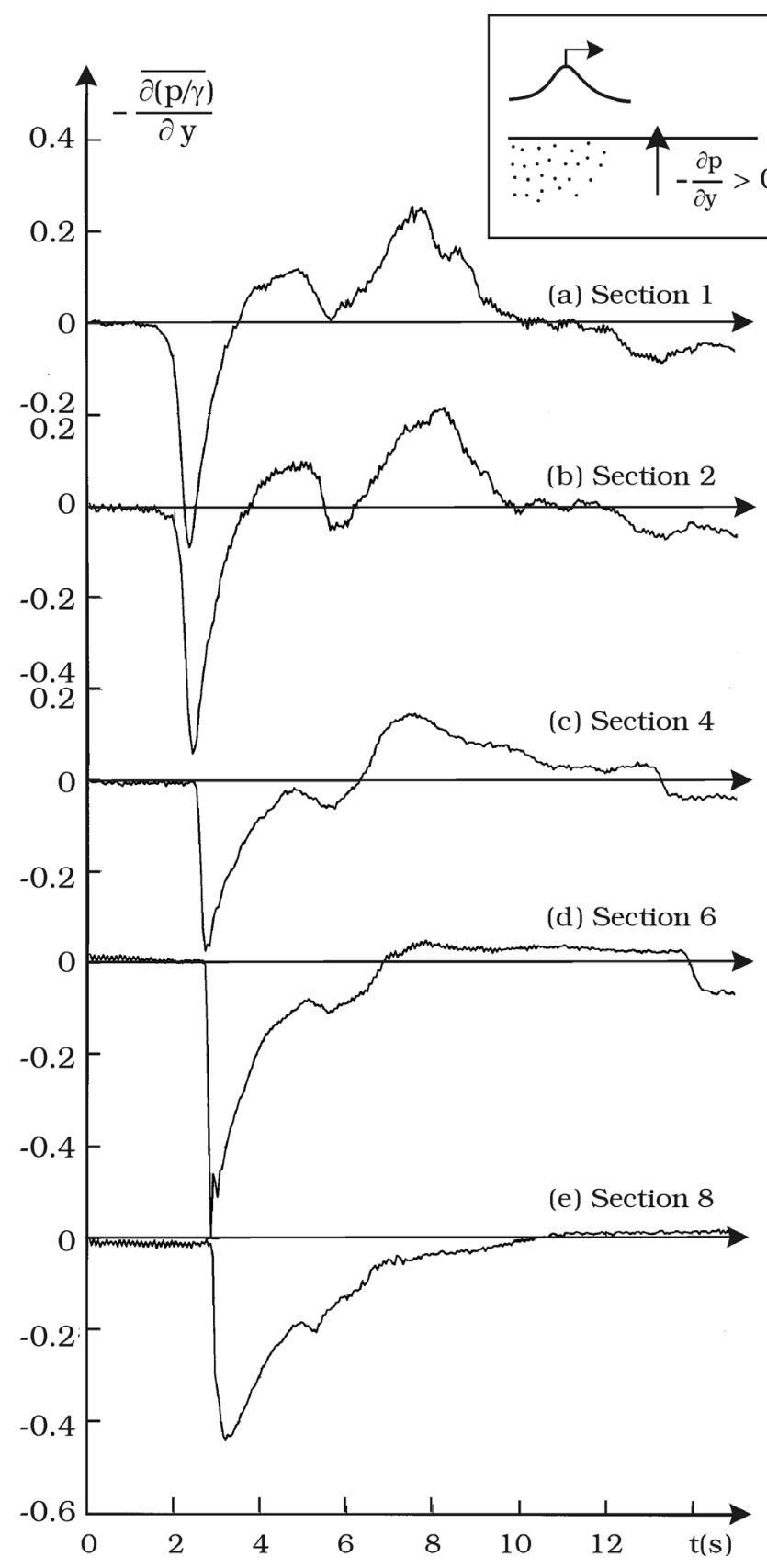

Figure 13. (a-e) Time variation of the mean pressure gradient in the soil at the surface layer of the bed. Positive pressure gradient corresponds to an upward directed pressure gradient force on the sediment.

Figure 14 for completeness. Figure $14 \mathrm{a}$ represents the shoaling and the runup stages while Figure $14 \mathrm{~b}$ represents the stages corresponding to rundown and hydraulic jump. Of particular interest is that $\left(-\frac{\partial p}{\partial y}\right)>0$ during the rundown, including the hydraulic jump stage (see Figure 14b), meaning that the sediment bed during this stage is subject to an upward directed force. This force (which is, from Figure 14b, ($\left.\left.\frac{\overline{\partial(p / \gamma)}}{\partial y}\right)_{\max } \sim O(0.05-0.25)\right)$ can reach values as much as up to approximately $30 \%$ of the submerged weight of the sediment (which is like $(s-1)(1-n) \sim O(0.9))$ toward the end of rundown stage. Clearly this has implications for sediment transport, as will be discussed in the next section. Here, $s$ is the specific gravity of sediment grains, $s=\gamma_{\mathrm{s}} / \gamma$, and $n$ is the porosity.

[48] At this juncture, it may be noted that Baldock et al. [2001] presented field measurements of pressure gradients in the surface layers of a sand beach, and compared the field data with a 1-D diffusion model. They found very large upward directed pressure gradients $(O(0.5-1)$ and larger $)$ frequently observed in the top $1.5 \mathrm{~cm}$ of the beach material. However, using realistic input parameters, they were unable to predict these large near-surface gradients, using their 1-D model.

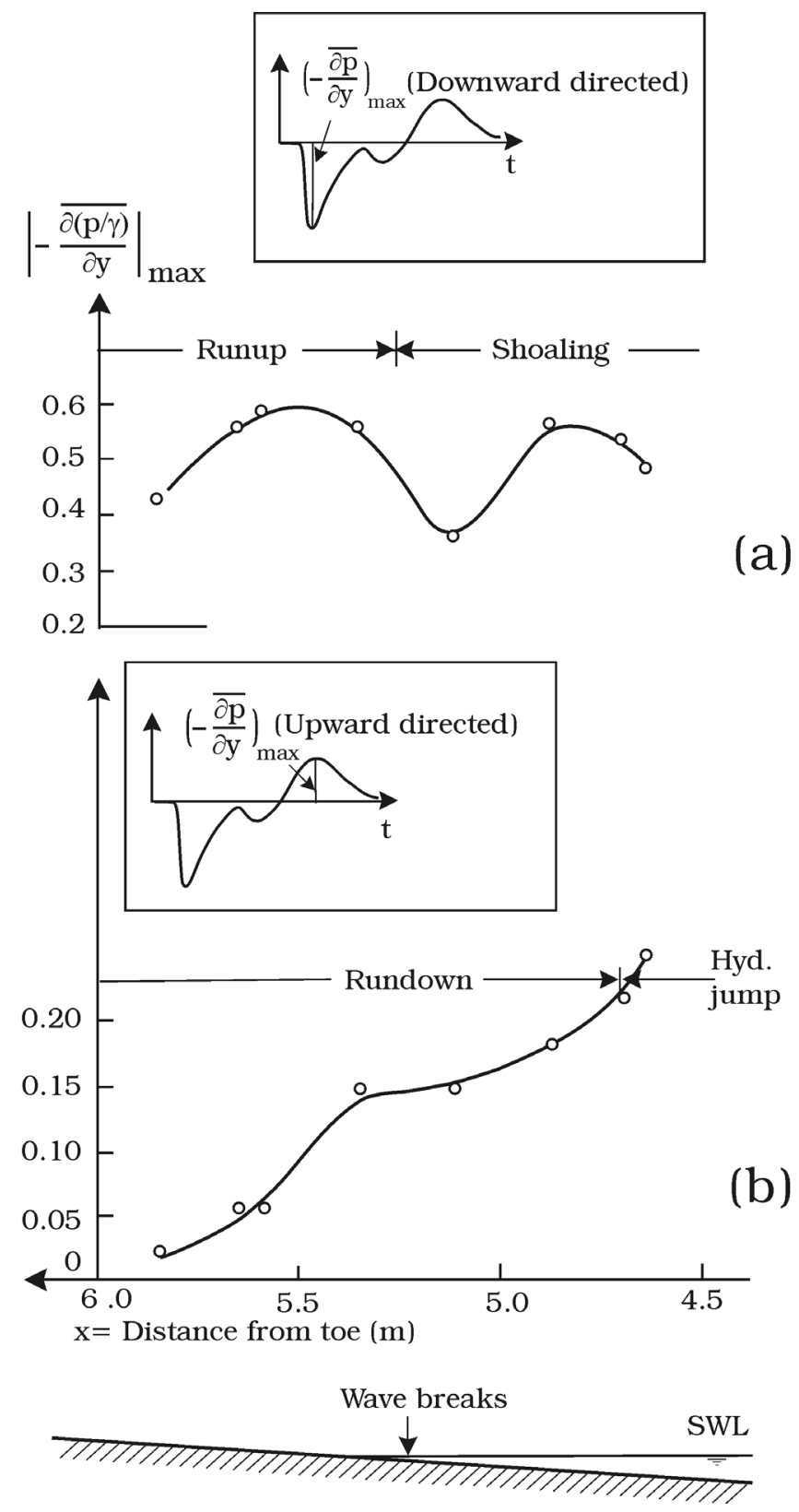

Figure 14. Variation along the horizontal direction of the maximum values of the mean pressure gradient at the surface layer of the bed (a) during the shoaling and runup stages and (b) during the rundown and hydraulic jump stages. 

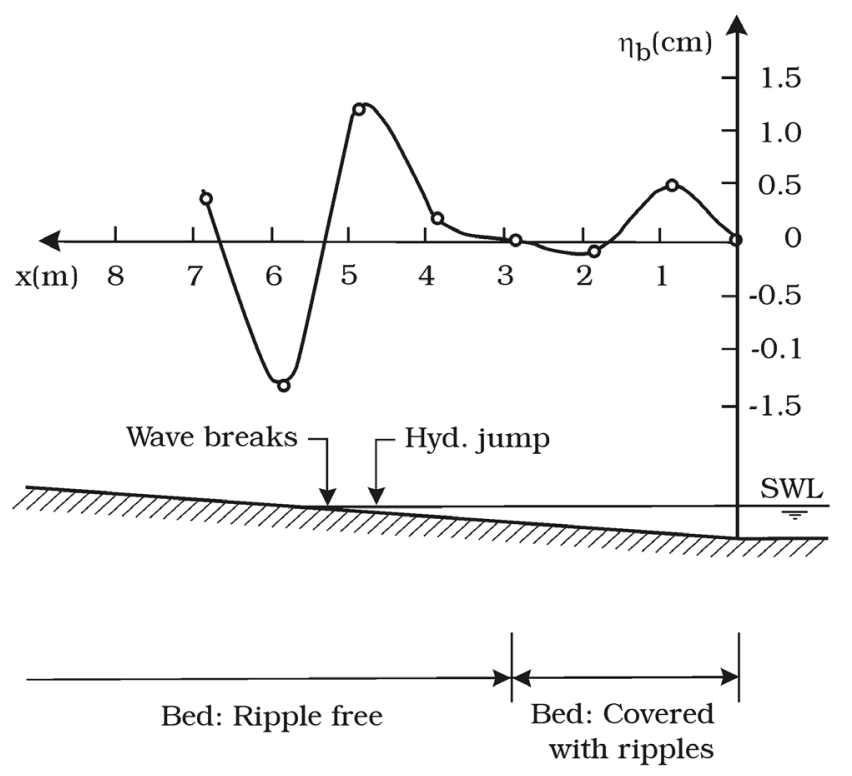

Figure 15. Bed profile after it is exposed to four waves.

[49] The above analysis is concerned with the pore water pressure gradient in the vertical direction. The pore water pressure gradient in the horizontal direction, $\partial p / \partial x$, may also be important in terms of bed stability. Just prior to the wave breaking, the onshore directed pressure gradient in the sediment bed near the bed surface can reach values that can cause general shear failure of the sediment locally [Madsen, 1974; Baldock and Holmes, 1998]. Madsen [1974] (and later, Baldock and Holmes [1998]) gave the following criterion for this failure:

$$
\left|\frac{\partial(p / \gamma)}{\partial x}\right|_{\max }=(s-1)(1-n) \tan \phi
$$

in which $\phi$ is the angle of internal friction. Madsen [1974] pointed out that the right-hand side of equation (9) is like 0.5 . For the present conditions, the latter value is found to be 0.52 , taking $s=2.65, n=0.45$ and $\phi=30^{\circ}$. The quantity $\partial p / \partial x$ was not measured in the present study. However, visual observations from the video recordings of the surface elevation indicated that the above critical value, 0.5 , is exceeded at about $0.4 \mathrm{~s}$ before the breaking occurs, implying that the sediment would fail locally at this instant owing to general shear failure. The visual observations also showed that the failure would likely be present over a period of $0.5 \mathrm{~s}$, starting $0.4 \mathrm{~s}$ prior to the wave breaking and continuing until about $0.1 \mathrm{~s}$ after. However, we were unable to check whether or not this soil failure was observable in the actual sedimentbed experiments as we became aware of this process later on. (We acknowledge Tom Baldock, who brought this aspect to our attention during the review of the present paper.) Nevertheless, given (1) the very short duration of the conditions leading to this kind of failure and (2) the very large, overwhelming Shields parameter values experienced during the runup and rundown stages in the sediment-bed tests (see section 5.2), the overall effect of this failure on the measured bed profile is expected to be minimal.

\subsection{Bed Profile}

[50] Figure 15 displays the bed profile measured after the bed was exposed to four successive waves separated with long breaks, as mentioned previously. The bed form obtained in this way was the cumulative effect of these, four successive waves. As the bed profile was measured over the entire length of the beach down to the toe $(x=0)$, the measured profile is given in Figure 15 for the entire length of the beach. Visual observations upon the completion of the experiment (with the bed exposed to the four waves) revealed that the bed was superimposed with ripples $(20-30 \mathrm{~cm}$ long and 4-5 cm high) for $x \approx 3 \mathrm{~m}$ while the rest of the bed (for $x>3 \mathrm{~m}$ ) was ripple free, the latter being due to the sheet-flow sediment transport, as will be discussed later. Figure 15 shows that the bed profile consists of alternating erosion and deposition areas. The general erosional and depositional pattern observed in Figure 15 is consistent with those from previous studies involving morphology due to plunging solitary waves [e.g., Kobayashi and Lawrence, 2004, Figure 4; Young et al., 2010, Figure 15]. The area over the length $0<x \approx 4 m$ will not be analyzed, as no measurements of the bed shear stress (in the rigid-bed experiments) and the pore water pressure were conducted over this area.

[51] Now, regarding the area $x>4 m$, Figure 15 shows that erosion occurs at the onshore side of the wave breaking, over the length $5.25 m<x<6.7 \mathrm{~m}$, and deposition occurs at the offshore side of the wave breaking, over the area $3 m<x<5.25 m$, with the maximum deposition taking place practically at the location where the hydraulic jump occurs. This behavior can be explained as follows.

[52] The Shields parameter,

$$
\theta=\frac{\overline{\tau_{0}} / \rho}{g(s-1) d-g\left[-\frac{\overline{\partial(p / \gamma)}}{\partial y}\right] d},
$$

can, to a first approximation, be calculated on the basis of the measured maximum bed shear stresses and maximum pressure gradients (Figures 9 and 14). This exercise gives $\theta=O(0.8-3)$ for the runup over $5.25 m<x<6.7 m$ where the bed erosion is observed. This value, $\theta=O(0.8-3)$, is presumably very high, so high (higher than $\theta>O(0.5)$ ) that the sediment transport takes place in the sheet flow regime, which was clearly visually evident in the present experiments for $x>3 \mathrm{~m}$. (For a detailed account of the sheet flow sediment transport, the reader is referred to, for example, Sumer et al. [1996].) Likewise, for the rundown stage over the same reach $5.25 m<x<6.7 \mathrm{~m}$, the Shields parameter is found to be $\theta=O(2-4)$, a value which is even higher than that of the runup stage. The reason why the Shields parameter is even higher in the rundown stage is largely due to the fact that the sediment is subject to an upward directed pressure gradient force during this phase (Figure 14b) while it is subject to a downward directed pressure gradient force at the runup stage; From the denominator of the right-hand side of equation (10), it can readily be seen that this corresponds to an increase of a factor of 1.5 in the value of the Shields parameter.

[53] Figure 16 displays the ratio of two Shields parameters $\theta_{u}$ and $\theta_{d}$. The Shields parameter is calculated by equation (10) where $\overline{\tau_{0}}$ is taken as $\left|\bar{\tau}_{0 \text { max }}\right|$ (see Figure 9), 


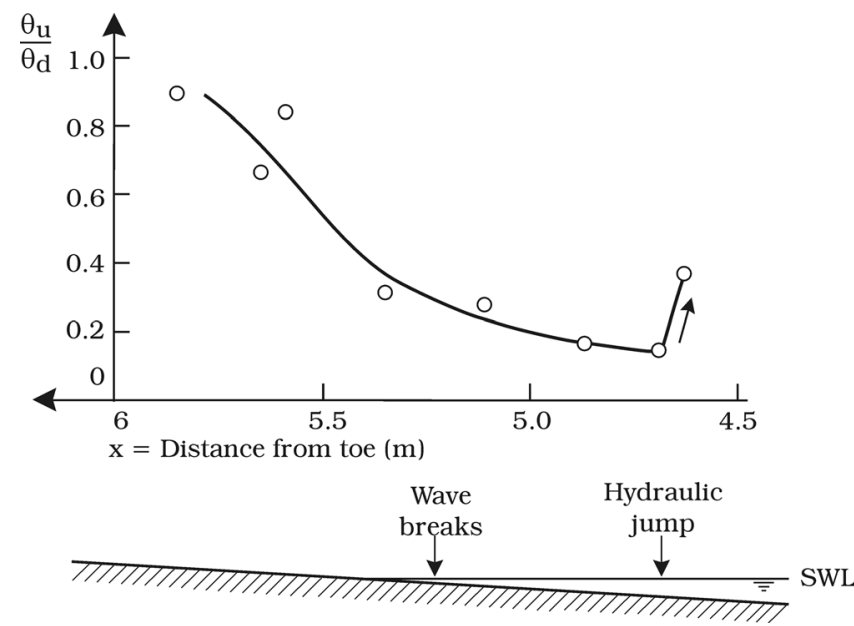

Figure 16. Ratio of the Shields parameters, $\theta_{u}$ and $\theta_{d}$, corresponding to the runup and rundown, respectively. See the text for the way in which $\theta_{u}$ and $\theta_{d}$ are calculated.

and $-\frac{\overline{\partial(p / \gamma)}}{\partial y}$ (see Figure 14) is taken as $1-\left.\frac{\overline{\partial(p / \gamma)}}{\partial y}\right|_{\max }$. The subindex $u$ in $\theta_{u}$ corresponds to the Shields parameter calculated for the runup, and the subindex $d$ in $\theta_{d}$ corresponds to that calculated for the rundown. The sign of the pressure gradient term in the denominator of the right-hand side of equation (10) is taken plus for the runup and minus for the rundown. Hence, the diagram in Figure 16 generally shows that $\theta_{u} / \theta_{d}<1$, implying that the sediment transport is directed offshore, supporting the description in the preceding paragraph.

[54] The above results indicate that the bed over $5.25 \mathrm{~m}<$ $x<6.7 m$ is eroded (rather "violently" as the sediment transport takes place in the sheet flow regime) during the runup and rundown stages, and more importantly, the eroded sediment is presumably transported in the offshore direction, thus resulting in erosion there, as (1) the sediment transport is larger during down-rush, and (2) furthermore there is no sediment supply from the onshore end of the beach. This is further illustrated by the decreasing trend in the ratio $\theta_{u} / \theta_{d}$ (from 0.9 to 0.2 ) in the offshore direction, which implies that the net offshore transport is increasing in magnitude in the offshore direction. This corresponds to a positive gradient in the net sediment transport, which from sediment continuity principles, is indeed consistent with the observed erosion in this region.

[55] In connection with the present calculation of the Shields parameter, equation (10), we note the following. The weight of grains in the denominator of the Shields parameter in equation (10), which is proportional to $g(\mathrm{~s}-1) d^{3}$, is reduced in the present formulation to $g(\mathrm{~s}-1) d^{3}-g\left[-\frac{\partial(p / \gamma)}{\partial y}\right] d^{3}$. Here the upward directed pressure gradient force acts on grains like a Froude-Krylov force [Sumer and Fredsøe, 2006, p. 129], $V(\partial p / \partial y)$, in which $V$ is the volume of the grain. Researchers have, in the past, incorporated the effect of pore pressure gradient (and seepage flow) in the Shields parameter; See Nielsen [1998], Baldock and Holmes [1998], Francalanci et al. [2008], and also the discussion to the latter paper by Baldock and Nielsen [2010], and the closure to the paper by Francalanci et al. [2010]. We believe that the above formu- lation qualitatively serves the purpose in the present study. We will not pursue the topic further, as it is beyond the scope of the study.

[56] Now, for the area $3 m<x<5.25 m$ where the sand is deposited (Figure 15), this area coincides with the location of the hydraulic jump, at/around section 1 (Figure 1). When inspected closely, our video recording shows that, with the formation of the hydraulic jump at this location, the bottom sediment is brought up into suspension in large quantities by the turbulence produced by the hydraulic jump (see the

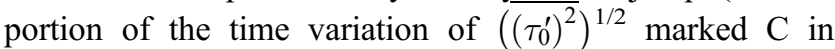
Figure 5a, over a time period of from $t \simeq 7 \mathrm{~s}$ to $t \simeq 10 \mathrm{~s}$ ). This sediment is transported offshore for a short while $(\mathrm{O}(0.5 \mathrm{~s}))$ and, with the reversal of the near-bed flow at $t \simeq 10 \mathrm{~s}$ (Figure 4a), it is brought back to the area where it was suspended, and eventually deposited there. This occurs over a time period from $t=10 \mathrm{~s}$ to $t=14 \mathrm{~s}$ (see Figure 4a).

\section{Discussion}

[57] We have, in the above analysis, utilized the bed shear stress data obtained in the rigid-bed experiments. It may be argued that the bed shear stress measured in the case of the rigid bed may not be a good approximation to the actual bed shear stresses experienced in the case of the sediment bed. Clearly the sediment bed, with a grain roughness of $d_{50}=$ $0.18 \mathrm{~mm}$, is not a smooth boundary. However, the grain Reynolds number in the experiments was $\operatorname{Re}_{g}=\left(d_{50} \sqrt{\overline{\tau_{0}} / \rho}\right) /$ $\nu<O(18)$ in which $\nu$ is the kinematic viscosity of the water $\left(\cong 0.01 \mathrm{~cm}^{2} / \mathrm{s}\right)$, and $\sqrt{\overline{\tau_{0}} / \rho}$ is the friction velocity, taken as $\sqrt{\overline{\tau_{0}} / \rho}=O(10 \mathrm{~cm} / \mathrm{s})$ for the highest flow (Figure 9). This indicates that the sediment bed, for the most part, acted as a hydraulically smooth boundary $\left(\operatorname{Re}_{g}<11.6\right)$, or as a transitional boundary $\left(11.6<\operatorname{Re}_{g}<70\right)$ at most, in the experiments. Hence the bed shear stress in the case of the sediment bed can, to a first approximation, be approximated by that measured in the rigid-bed experiments. It may be noted, however, that the results given in the previous section should be interpreted with some caution as whether or not the bed shear stresses measured in the rigid-bed tests could be reproduced in the sediment-bed tests (where the bed is moving) is unknown to the writers.

[58] Another effect regarding the bed shear stress in the case of a sediment bed under waves is the influence of exfiltration and infiltration on the bed shear stress. This effect has been investigated experimentally [Conley and Inman, 1994] and numerically [Lohmann et al., 2006] in ordinary wave boundary layers. It was found that the bed shear stress is increased during infiltration (corresponding to the crest half period of the wave), and decreased during exfiltration (corresponding to the trough half period) [see Conley and Inman, 1994, Figure 9]. Although this effect will not be present in solitary waves in the way as they are present in the case of ordinary wave boundary layers, nevertheless the infiltration phase is expected to occur quite strongly in the present case too. Likewise, the bed shear stress should be expected to be affected by the infiltration and exfiltration processes over the swash zone as well. Clearly the change in the bed shear stress due to the presence of the infiltration and exfiltration will influence the sediment transport (and hence the bed morphology), and therefore these processes need to be 
taken into account in a numerical modeling exercise aiming at predicting the beach morphology under solitary waves.

[59] A third effect is the influence of turbulence in the bed shear stress on sediment transport. As discussed in the preceding paragraphs in conjunction with Figure 10, turbulence in the bed shear stress is similar to that generated in steady (or wave) boundary layers in the shoaling (Figure 10a) and rundown (Figure 10b) stages. However, it undergoes a massive increase in the runup (Figure 10a), and during the hydraulic jump (Figure 10b). As mentioned previously, this is externally generated turbulence. The effect of externally generated turbulence on sediment transport has been investigated by Sumer et al. [2003]. The latter authors found that the effect of turbulence on the sediment transport is very significant. Hence this effect also needs to be taken into consideration in a numerical modeling exercise of beach morphology.

\section{Conclusions}

[60] Two parallel experiments involving the evolution and runup of plunging solitary waves on a sloping bed were conducted. The first utilized a rigid bed, allowing direct (hot film) measurements of bed shear stresses, while the second utilized a sediment bed, allowing for the measurement of pore water pressures, pressure gradient forces, as well as for observation of the resulting morphological changes. The two experimental conditions were maintained as similar as possible, both in terms of the generated waves and initial bottom configuration, so that the observations from both sets of experiments could be related to each other. The following conclusions are drawn.

[61] 1. The bed shear stress measurements showed that the mean bed shear stress increases tremendously (with respect to that in the approaching wave boundary layer) during the runup and rundown stages. This increase can be by as much as $\mathrm{O}(8)$.

[62] 2. These experiments also showed that the RMS value of the fluctuating component of the bed shear stress is also affected; the latter increases (with respect to that in the approaching boundary layer) by as much as $\mathrm{O}(2)$ in the runup and hydraulic jump stages.

[63] 3. The pore water pressure measurements showed that the sediment at (or near) the surface of the bed experiences upward directed pressure gradient forces during the rundown and hydraulic-jump stages. This force is caused by the delay in the pore pressure in responding to the fluid loading (infiltration and exfiltration).

[64] 4. These measurements indicated that the magnitude of this force can reach values as much as $30 \%$ of the submerged weight of the sediment, which has significant implications for sediment transport.

[65] 5. Visual observations in the sediment-bed experiments revealed that the sediment transport occurs in the sheet flow regime for a substantial portion of the beach including the area where the sequence from the wave breaking to the runup, to the rundown, and to the hydraulic jump takes place (Figure 15).

[66] 6. The measured bed morphology (Figure 15) is explained qualitatively in terms of the measured bed shear stress and upward/downward directed pore water pressure gradient forces.

\section{Notation}

[67] The following symbols are used in this paper.

$h=$ offshore water depth.

$H=$ wave height.

$p=$ pore water pressure in excess of the static pressure.

$R=$ maximum runup elevation from SWL.

$s=$ specific gravity of sediment grains.

$t=$ time.

$T=$ time scale characterizing the width of the surface elevation time series, equation (3).

$U_{m}=$ maximum value of water particle velocity.

$x=$ horizontal distance from toe of the beach.

$y=$ vertical distance measured from the bed upward.

$\gamma=$ specific weight of water.

$\eta=$ surface elevation measured from the still water level (SWL).

$\eta_{b}=$ bed elevation.

$\theta=$ Shields parameter.

$\xi_{s}=$ solitary wave surf similarity parameter, equation (4).

$\rho=$ water density.

$\tau_{0}=$ bed shear stress.

$\overline{\tau_{0}}=$ mean bed shear stress.

$\tau_{0}^{\prime}=$ fluctuating part of the bed shear stress.

$\omega=$ angular frequency, defined by equation (2).

[68] Acknowledgments. This study has been partially funded by the Danish Council for Strategic Research through the research program "Seabed and Wind Farm Interaction." We would like to thank the reviewers (one of whom was Tom Baldock) for their invaluable comments.

\section{References}

Alfredson, P. H., A. V. Johansson, J. H. Haritonidis, and H. Eckelmann (1988), The fluctuating wall shear stress and the velocity field in the viscous sublayer, Phys. Fluids, 31, 1026-1033, doi:10.1063/1.866783.

Alsina, J. M., S. Falchetti, and T. E. Baldock (2009), Measurements and modeling of the advection of suspended sediment in the swash zone by solitary waves, Coastal Eng., 56, 621-631, doi:10.1016/j.coastaleng. 2009.01.007.

Baldock, T. E., and P. Holmes (1998), Seepage effects on sediment transport by waves and currents, paper presented at 26th International Conference on Coastal Engineering, Am. Soc. of Civ. Eng., Copenhagen.

Baldock, T. E., and P. Nielsen (2010), Discussion of "Effect of seepageinduced nonhydrostatic pressure distribution on bed-load transport and bed morphodynamics" by S. Francalanci, G. Parker and L. Solari, J. Hydraul. Eng., 1, 77-79, doi:10.1061/(ASCE)HY.1943-7900.0000015.

Baldock, T. E., A. J. Baird, D. P. Horn, and T. Mason (2001), Measurements and modeling of swash-induced pressure gradients in the surface layers of a sand beach, J. Geophys. Res., 106(C2), 2653-2666, doi:10.1029/1999JC000170.

Baldock, T. E., D. Cox, T. Maddux, J. Killian, and L. Fayler (2009), Kinematics of breaking tsunami wavefronts: A data set from large scale laboratory experiments, Coastal Eng., 56, 506-516, doi:10.1016/j.coastaleng. 2008.10.011.

Barnes, M. P., T. O. O’Donoghue, J. M. Alsina, and T. E. Baldock (2009), Direct bed shear stress measurements in bore-driven swash, Coastal Eng., 56, 853-867, doi:10.1016/j.coastaleng.2009.04.004.

Battjes, J. A. (1974), Surf similarity, paper presented at 14th International Conference on Coastal Engineering, Am. Soc. of Civ. Eng., Copenhagen.

Brocchini, M., and T. E. Baldock (2008), Recent advances in modeling swash zone dynamics: Influence of surf-swash interaction on nearshore hydrodynamics and morphodynamics, Rev. Geophys., 46, RG3003, doi:10.1029/2006RG000215.

Butt, T., and P. Russell (2000), Hydrodynamics and cross-shore sediment transport in the swash zone of natural beaches: A review, J. Coastal Res., $16,255-268$

Chang, Y.-H., K.-S. Hwang, and H.-H. Hwung (2009), Large-scale laboratory measurements of solitary wave inundation on a 1:20 slope, Coastal Eng., 56, 1022-1034, doi:10.1016/j.coastaleng.2009.06.008.

Conley, D. C., and D. L. Inman (1994), Ventilated oscillatory boundary layers, J. Fluid Mech., 273, 261-284, doi:10.1017/S002211209400193X. 
Eckelmann, H. (1974), The structure of the viscous sublayer and the adjacent wall region in a turbulent channel flow, J. Fluid Mech., 65, 439-459, doi:10.1017/S0022112074001479.

Elfrink, B., and T. Baldock (2002), Hydrodynamics and sediment transport in the swash zone: A review and perspectives, Coastal Eng., 45, 149-167, doi:10.1016/S0378-3839(02)00032-7.

Francalanci, S., G. Parker, and L. Solari (2008), Effect of seepage-induced nonhydrostatic pressure distribution on bed-load transport and bed morphodynamics, J. Hydraul. Eng., 134, 378-389, doi:10.1061/(ASCE)0733-9429 (2008)134:4(378)

Francalanci, S., G. Parker, and L. Solari (2010), Closure to "Effect of seepage-induced nonhydrostatic pressure distribution on bed-load transport and bed morphodynamics" by S. Francalanci, G. Parker and L. Solari, J. Hydraul. Eng., 1, 79-82, doi:10.1061/(ASCE)HY.1943-7900.0000160.

Fuhrman, D. R., and P. A. Madsen (2008), Surf similarity and solitary wave runup, J. Waterw. Port Coastal Ocean Eng., 134, 195-198.

Fuhrman, D. R., J. Fredsøe, and B. M. Sumer (2009a), Bed slope effects on turbulent wave boundary layers: 1 . Model validation and quantification of rough-turbulent results, J. Geophys. Res., 114, C03024, doi:10.1029/ 2008JC005045.

Fuhrman, D. R., J. Fredsøe, and B. M. Sumer (2009b), Bed slope effects on turbulent wave boundary layers: 2. Comparison with skewness, asymmetry, and other effects, J. Geophys. Res., 114, C03025, doi:10.1029/ 2008JC005053.

Grilli, S. T., I. A. Svendsen, and R. Subramanya (1997), Breaking criterion and characteristics for solitary waves on slopes, J. Waterw. Port Coastal Ocean Eng., 123, 102-112.

Hanratty, T. J., and J. A. Campbell (1983), Measurements of wall shear stress, in Fluid Mechanics Measurements, edited by R. J. Goldstein, pp. 559-615, Hemisphere, Washington, D.C.

Heller, V., J. Unger, and W. Hager (2005), Tsunami run-up: A hydraulic perspective, J. Hydraul. Eng., 131, 743-747, doi:10.1061/(ASCE) 0733-9429(2005)131:9(743).

Hsiao, S.-C., T.-W. Hsu, T.-C. Lin, and Y.-H. Chang (2008), On the evolution and run-up of breaking solitary waves on a mild sloping beach, Coastal Eng., 55, 975-988, doi:10.1016/j.coastaleng.2008.03.002.

Jensen, A., G. K. Pedersen, and D. J. Wood (2003), An experimental study of wave run-up at a steep beach, J. Fluid Mech., 486, 161-188, doi:10.1017/S0022112003004543.

Jensen, B. L., B. M. Sumer, and J. Fredsøe (1989), Turbulent oscillatory boundary layers at high Reynolds numbers, J. Fluid Mech., 206 , 265-297, doi:10.1017/S0022112089002302.

Kobayashi, N., and E. A. Karjadi (1994), Surf-similarity parameter for breaking solitary-wave runup, J. Waterw. Port Coastal Ocean Eng., 120, 645-650.

Kobayashi, N., and A. R. Lawrence (2004), Cross-shore sediment transport under breaking solitary waves, J. Geophys. Res., 109, C03047, doi:10.1029/2003JC002084.

Lambe, T. W., and R. V. Whitman (1969), Soil Mechanics, John Wiley, New York.

Li, Y., and F. Raichlen (2001), Solitary wave runup on plane slopes, J. Waterw. Port Coastal Ocean Eng., 127, 33-44, doi:10.1061/(ASCE) 0733-950X(2001)127:1(33)

Li, Y., and F. Raichlen (2002), Non-breaking and breaking solitary wave run-up, J. Fluid Mech., 465, 295-318.

Li, Y., and F. Raichlen (2003), Energy balance model for breaking solitary wave runup, J. Waterw. Port Coastal Ocean Eng., 129, 47-59, doi:10.1061/(ASCE)0733-950X(2003)129:2(47).

Lin, P., K.-A. Chang, and P. L.-F. Liu (1999), Runup and rundown of solitary waves on sloping beaches, J. Waterw. Port Coastal Ocean Eng., 125, 247-255, doi:10.1061/(ASCE)0733-950X(1999)125:5(247).

Liu, P. L.-F., Y. S. Park, and E. A. Cowen (2007), Boundary layer flow and bed shear stress under a solitary wave, J. Fluid Mech., 574, 449-463, doi:10.1017/S0022112006004253.

Lodahl, C. R., B. M. Sumer, and J. Fredsøe (1998), Turbulent combined oscillatory flow and current in a pipe, J. Fluid Mech., 373, 313-348, doi:10.1017/S0022112098002559.

Lohmann, I. P., J. Fredsøe, B. M. Sumer, and E. D. Christensen (2006), Large eddy simulation of the ventilated wave boundary layer, J. Geophys. Res., 111, C06036, doi:10.1029/2005JC002946.

Madsen, O. S. (1974), Stability of a sand bed under breaking waves, paper presented at 14th International Conference on Coastal Engineering, Am. Soc. of Civ. Eng., Copenhagen.

Madsen, P. A., D. R. Fuhrman, and H. A. Schäffer (2008), On the solitary wave paradigm for tsunamis, J. Geophys. Res., 113, C12012, doi:10.1029/2008JC004932.
Masselink, G., and J. A. Puleo (2006), Swash-zone morphodynamics, Cont. Shelf Res., 26, 661-680, doi:10.1016/j.csr.2006.01.015.

Mei, C. C., and M. A. Foda (1981), Wave-induced responses in a fluid filled poroelastic solid with a free surface: A boundary layer theory, Geophys. J. R. Astron. Soc., 66, 597-631.

Mitchell, J. E., and T. J. Hanratty (1966), A study of turbulence at a wall using an electrochemical wall shear-stress meter, J. Fluid Mech., 26, 199-221, doi:10.1017/S0022112066001174.

Nielsen, P. (1998), Coastal groundwater dynamics, in Coastal Dynamics' 97, pp. 546-555, Am. Soc. of Civ. Eng., Reston, Va.

Nielsen, P., and S. L. Dunn (1998), Manometer tubes for coastal hydrodynamics investigation, Coastal Eng., 35, 73-84, doi:10.1016/S0378-3839 (98)00021-0.

Sandven, R., E. Husby, J. E. Husby, J. Jønland, K. O. Roksvåg, F. Staehli, and R. Tellugen (2007), Development of a sampler for measurement of gas content in soils, J. Waterw. Port Coastal Ocean Eng., 133, 3-13, doi:10.1061/(ASCE)0733-950X(2007)133:1(3)

Seelam, J. K., and T. E. Baldock (2009), Direct bed stress measurements under solitary tsunami-type waves and breaking tsunami wave fronts, paper 49 in Proceedings of Coastal Dynamics 2009: Impacts of Human Activities on Dynamic Coastal Processes, edited by M. Mizuguchi and S. Sato, World Sci., Hackensack, N. J.

Sumer, B. M., and J. Fredsøe (2006), Hydrodynamics Around Cylindrical Structures, rev. ed., World Sci., Hackensack, N. J.

Sumer, B. M., M. M. Arnskov, N. Christiansen, and F. E. Jørgensen (1993), Two-component hot-film probe for measurements of wall shear stress, Exp. Fluids, 15, 380-384, doi:10.1007/BF00191776.

Sumer, B. M., A. Kozakiewicz, J. Fredsøe, and R. Deigaard (1996), Velocity and concentration profiles in the sheet flow layer of movable bed, J. Hydraul. Eng., 122, 549-558, doi:10.1061/(ASCE)0733-9429 (1996)122:10(549)

Sumer, B. M., L. H. C. Chua, N.-S. Cheng, and J. Fredsøe (2003), The influence of turbulence on bedload sediment transport, J. Hydraul. Eng., 129, 585-596, doi:10.1061/(ASCE)0733-9429(2003)129:8(585).

Sumer, B. M., P. M. Jensen, L. B. Sørensen, J. Fredsøe, P. L.-F. Liu, and S. Carstensen (2010), Coherent structures in wave boundary layers. Part 2. Solitary motion, J. Fluid Mech., 646, 207-231, doi:10.1017/ S0022112009992837.

Synolakis, C. (1987), The runup of solitary waves, J. Fluid Mech., 185, 523-545, doi:10.1017/S002211208700329X

Synolakis, C., and J. E. Skjelbreia (1993), Evolution of maximum amplitude of solitary waves on plane beaches, J. Waterw. Port Coastal Ocean Eng., 119, 323-342, doi:10.1061/(ASCE)0733-950X(1993)119:3(323).

Ting, F. C. K. (2006), Large-scale turbulence under a solitary wave, Coastal Eng., 53, 441-462, doi:10.1016/j.coastaleng.2005.11.004.

Ting, F. C. K. (2008), Large-scale turbulence under a solitary wave: Part 2 , Forms and evolution of coherent structures, Coastal Eng., 55, 522-536, doi:10.1016/j.coastaleng.2008.02.018.

Ting, F. C. K., and J. T. Kirby (1995), Dynamics of surf-zone turbulence in a strong plunging breaker, Coastal Eng., 24, 177-204, doi:10.1016/03783839(94)00036-W.

Tonkin, S., H. Yeh, F. Kato, and S. Sato (2003), Tsunami scour around a cylinder, J. Fluid Mech., 496, 165-192, doi:10.1017/S0022112003006402.

Vittori, G., and P. Blondeaux (2008), Turbulent boundary layer under a solitary wave, J. Fluid Mech., 615, 433-443, doi:10.1017/S0022112008003893.

Xiao, H., Y. L. Young, and J. H. Prevost (2010), Hydro- and morphodynamic modeling of breaking solitary waves over a fine sand beach. Part II: Numerical simulation, Mar. Geol., 269, 119-131, doi:10.1016/ j.margeo.2009.12.008.

Young, Y. L., H. Xiao, and T. Maddux (2010), Hydro- and morphodynamic modeling of breaking solitary waves over a fine sand beach. Part I: Experimental study, Mar. Geol., 269, 107-118, doi:10.1016/j. margeo. 2009.12.009.

B. Ceren and M. B. Sen, Grontmij I Carl Bro A/S, DK-2600 Glostrup, Denmark. (Barkin.Ceren@grontmij-carlbro.dk; Berke.Sen@grontmijcarlbro.dk)

J. Fredsøe, D. R. Fuhrman, M. Sottile, B. M. Sumer, and L. Zilioli, Coastal, Maritime and Structural Engineering, Department of Mechanical Engineering, Technical University of Denmark, DK-2800 Kgs. Lyngby, Denmark. (jf@mek.dtu.dk; drf@mek.dtu.dk; matteo.sottile@gmail.com; bms@mek.dtu.dk; luca.zilioli@gmail.com)

I. Karagali, Wind Energy Department, Risø National Laboratory for Sustainable Energy, DK-4000 Roskilde, Denmark. (ioanna.karagali@ risoe.dk) 